\title{
中国银口天竺鲷属鱼类的分类厘定
}

\author{
俞正森 ${ }^{\circledR 1}$, 宋娜 ${ }^{1}$, 本村浩之 ${ }^{2}$, 高天翔 ${ }^{3 *}$
}

1. 中国海洋大学水产学院, 山东青岛 266003; 2. 鹿儿岛大学综合研究博物馆, 鹿儿岛 890-0065; 3. 浙江海洋大学水产学院, 浙江舟山 316022

摘要: 本研究检视了采自中国沿海的银口天竺鲖属标本314尾, 形态学鉴定为8种: 斑鯺银口天䇥鲷(Jaydia carinata (Cuvier, 1828))、细条银口天竺鲷(J. lineata (Temminck \& Schlege, 1842))、新几内亚银口天答鲖(J. novaeguineae (Valenciennes, 1832))、黑鳃银口天竺鲷(J. poeciloptera (Cuvier, 1828))、史密斯氏银口天竺鲷(J. smithi Kotthaus 1970)、横带银口天矢鲷( J. striata (Smith \& Radcliffe, 1912))、印度洋银口天竺鲖(J. striatodes (Gon, 1997))和黑边银口天筷鲷 (J. truncata (Bleeker, 1854))。结合GenBank中的同种序列, 对史密斯氏银口天竺鲖进行DNA条形码分析, 发现中国群体和地中海群体分为两个组 群, 两者平均组间遗传距离为 0.044 , 表明其中存在隐存种。因该种模式产地为亚丁湾, 推测中国种群为隐存种Jaydia sp.。结 合标本和文献考证, 我们认为中国已知有银口天答鲷属鱼类9种, 未采集到的烟台银口天答鲷J. tchefouensis (Fang, 1942)可能 为J. lineata次定同种异名。我们整理了各种的同种异名、形态特征和地理分布，编制了检索表，探讨了分类问题，修订了错 误。中国已记录物种J. ellioti、J. arafurae、J. albomarginata实际为J. truncata、J. poeciloptera和J. novaeguineae。 关键词: 银口天焦鲷属; 分类; 形态特征; DNA条形码; 检索表

俞正森, 宋娜, 本村浩之, 高天翔 (2021) 中国银口天竺鲖属鱼类的分类厘定. 生物多样性, 29, 971-979. doi: 10.17520/biods.2020320. Yu ZS, Song N, Motomura H, Gao TX (2021) Taxonomic revision of the cardinalfish genus Jaydia in China. Biodiversity Science, 29, 971-979. doi: 10.17520/biods.2020320.

\section{Taxonomic revision of the cardinalfish genus Jaydia in China}

Zhengsen $\mathrm{Yu}^{(\mathrm{D} 1}{ }^{\text {, Na Song }}{ }^{1}$, Hiroyuki Motomura², Tianxiang $\mathrm{Gao}^{3^{*}}$

1 Fisheries College, Ocean University of China, Qingdao, Shandong 266003, China

2 Kagoshima University Museum, Kagoshima 890-0065, Japan

3 School of Fishery, Zhejiang Ocean University, Zhoushan, Zhejiang 316022, China

\section{ABSTRACT}

Aim: Cardinalfishes (Apogonidae) are one of the numerically dominant reef fish families. The taxonomy of cardinalfish genus Jaydia in China was unclear for a long time. This study aims to revise the the taxonomy of the genus from China. Methods: The taxonomic revision was based on comprehensive examination of specimens and review of literatures. Jaydia sp. was distinguished from J. smithi by molecular comparison.

Results: Eight species were identified morphologically, including Jaydia carinata (Cuvier, 1828), J. lineata (Temminck \& Schlege, 1842), J. novaeguineae (Valenciennes, 1832), J. poeciloptera (Cuvier, 1828), J. smithi Kotthaus 1970, J. striata (Smith \& Radcliffe, 1912), J. striatodes (Gon, 1997), J. truncata (Bleeker, 1854). But J. tchefouensis was not found from China seas. The results of molecular analysis of J. smithi showed the Chinese population and the Mediterranean population formed two exclusive lineages which have obvious interspecific-level mean genetic distance (0.044). The previously recorded species from China, J. ellioti, J. arafurae, J. albomarginata, and J. smithi, should be revised as J. truncata, J. poeciloptera, J. novaeguineae, and Jaydia sp., respectively. Jaydia tchefouensis may be a junior synonym of J. lineata. The synonyms, distribution, morphological diagnosis and description, and a key to species were provided. The taxonomic problems were also discussed.

Conclusion: Nine Jaydia species were recognized from China. Our results will promote the taxonomic study of family Apogonidae.

Key words: Jaydia; taxonomy; morphological characters; DNA barcodes; key of species

收稿日期: 2020-08-11; 接受日期: 2020-12-27

基金项目: 国家自然科学基金(41176117)

* 通讯作者 Author for correspondence. E-mail: gaotianxiang0611@163.com 
天竺鲷科 (Apogonidae) 隶属于鲈形目 (Perciformes)鲇亚目(Percoidei) (Fraser, 1972; Nelson, 2006; Mabuchi et al, 2014)。近年来, 国外学者通过 分子系统发育分析认为天竺鲖科应归属于虾虎鱼 目(Gobiiformes)天竺鲷亚目(Apogonoidei) (Thacker, 2009; Thacker \& Rojel, 2009; Thacker et al, 2015)。 但该分类结果尚未被分类学者所采纳(Fraser, 2011, 2014; Mabuchi et al, 2014; Gon et al, 2015; Fraser \& Prokofiev, 2016)。天竺鲷科分为4亚科40属约381种 (Fricke et al, 2020a, b), 广泛分布于印度洋、太平洋 和大西洋的热带及亚热带海域, 少数物种分布于淡 水和温带近海(Mabuchi et al, 2014)。银口天竺鲖属 (Jaydia)隶属于天竺鲷科天竺鲷亚科(Apogoninae), 为一类栖息于泥沙底的小型鱼类(体长一般小于 120 $\mathrm{mm})$, 目前世界上已知有 18 个有效种, 广泛分布于印 度洋到西太平洋近海(Mabuchi et al, 2014; Fricke et al, 2020a, b)。

Smith (1961)在西印度洋研究了两种天竺鲷属 鱼类黑边天竺鲖(Apogon ellioti)和奎氏天等鲷(A. queketti), 发现它们具有圆形尾鯺和前鳃盖骨边缘 锯齿退化这些特征, 认为ellioti和queketti应不属于 Apogon属, 并建立了新属Jaydia来容纳这两个物 种。Fraser (1972)基于比较骨学研究将Jaydia列为 Apogon的同属异名。Gon (1997)认为Jaydia的种类 具有前鳃盖骨边缘锯齿退化、第四背鯺鳍棘最 长、具发光器官等共有衍征, 在属Apogon中Jaydia 为一单系群, 应为Apogon的一有效亚属。Mabuchi 等(2014)基于分子系统发育分析和比较形态学研究 对天竺鲖科进行分类修订, 结果支持Jaydia有效属 的分类地位, Jaydia被提升为属。Cuvier (1828)描述 了Apogon carinatus (= J. carinata) 和A. poecilopterus (= J. poeciloptera)。Gon (1997)认为Cuvier (1828)错 误地描述了 poecilopterus第一背鯺具6枚鰙棘, 误导 Bleeker (1849) 命名了新种 Apogon glaga (= J. poecilopterus)。Bleeker (1854) 建立了新属 Apogonichthys (原天竺鲷属), 将carinatus和glaga归 入Apogonichthys属。受此影响, 中国的鱼类学者在 记录银口天竺鲖属鱼类时, 长期使用了属名 Apogonichthys (王以康, 1958; 成庆泰, 1959a, b, 1987; 成庆泰等, 1962; 沈根媛, 1985)。Gon (1997) 修订了银口天竺鲷属(当时被认为是天竺鲖属的亚 属), 鉴定出 10 个有效种和 9 个次定同种异名, 并将 10
个有效种划分为 3 个种团(species group): (1)黑边银 口天竺鲷种团(truncata group), 包含truncata, smithi 和hungi, 都具有臀部发光器官; (2)斑鯺银口天竺鲷 种团(carinata group), 包含 carinata, poeciloptera和 queketti, 具有前鳃盖骨边缘及后故骨后缘光滑、体 侧具斑纹(有时连成线条) 和覆膜无黑色素分布等特 征; (3)细条银口天答鲷种团 (lineata group), 包含 lineata, novaeguineae, striata和striatodes, 具有尾神 经骨缺失、体侧有 7-11窄横带、胸鰙鯺条数 15 和 发达上鳃耙数2-3等特征。

中国共记录有银口天竺鲖属命名种 12 种。 Fang (1942) 描述了采于中国烟台的新种Apogon tchefouensis。成庆泰(1959b)首次较为全面地记录 了中国银口天竺鲷属鱼类, 包括 Apogonichthys striatus、A. lineatus、A. arafurae、A. albomarginatus、 A. carinatus 和 A. ellioti 共 6 个命名种, 其中 A. striatus、A. arafurae 和A. albomarginatus为中国的 新记录种。之后, 除属名及中文名的变动外, 国内 学者基本沿用了成庆泰(1959b)的记述(成庆泰等, 1962; 沈根媛, 1985; 沈世杰, 1993; 孙典荣和陈铮, 2013; 陈大刚和张美昭, 2016)。Gon (1997)在中国 南部沿海和台湾记录了另外 4 个银口天竺鲷属命名 种 (novaeguinae、poeciloptera、smithi 和 truncata), 并报道了新种Apogon (Jaydia) striatodes。

长期以来, 中国银口天竺鲖属鱼类存在学名误 用、错误记录和形态特征描述不充分及错误等情 况。本研究在检视标本的基础上, 全面考察了中国 银口天竺鲖属鱼类的已有记载, 对该属进行分类整 理, 开展形态特征全面描述和深入的比较分析, 对 鱼种学名逐一校正, 探讨了各物种的地理分布和分 类问题, 以期为深入开展中国银口天竺鲷属乃至天 竺鲖科鱼类的系统分类研究打下基础。

\section{材料和方法}

\section{1 实验材料}

本研究检视了保存于中国海洋大学渔业生态学 实验室(Fishery Ecology Laboratory, Ocean University of China, OUC_FEL)、浙江海洋大学渔业生态与生 物多样性实验室(Fishery Ecology and Biodiversity Laboratory, Zhejiang Ocean University, ZJOU_FEBL)、 中国科学院海洋研究所 (Institute of Oceanology, Chinese Academy of Sciences, IOCAS)、中国科学院 
南海海洋研究所 (South China Sea Institute of Oceanology, Chinese Academy of Sciences, SCSIOCAS) 和浙江自然历史博物馆(Zhejiang Museum of Natural History, ZMNH)标本共314尾。

\section{2 形态学}

使用电子数显卡尺量度可测量形态特征, 精确 到 $0.1 \mathrm{~mm}$ 。比值精确到 0.1 。测量方法如图1所示。 图1不便示意的测量特征及计数特征按照附录 1 中 所述的方法进行测量和计数。如无特别说明, 文中 出现的标本长度均为体长。

\section{3 遗传学分析}

前期研究发现中国存在一个与史密斯氏银口天 竺鲖形态上难以区分但分子差异明显的物种(Jaydia sp.), 本研究使用分子生物学方法来区分它们。

取Jaydia sp. 适量肌肉组织, 采用酚-氯仿方法提 取基因组DNA, 乙醇沉淀后的基因组DNA溶解于 $100 \mu \mathrm{L}$ 蒸馏水中, $4^{\circ} \mathrm{C}$ 保存备用。用于扩增线粒体 DNA COI 片段的引物为 FishF1 (5'-TCAACCAA CCACAAAGACATTGGCAC-3') 和 FishR2 (5'ACTTCAGGGTGACCGAAGAATCAGAA-3') (Ward et al, 2005)。PCR反应体系为 $25 \mu \mathrm{L}$ : Taq酶 $0.25 \mu \mathrm{L}$, DNA模板 $1 \mu \mathrm{L}$, 正、反向引物各 $1 \mu \mathrm{L}, \mathrm{dNTP} 2 \mu \mathrm{L}, 10$ $\times$ PCR缓冲液 $2.5 \mu \mathrm{L}$, 去离子水 $17.25 \mu \mathrm{L}$ 。 PCR反应 条件为: $94^{\circ} \mathrm{C}$ 预变性 $5 \mathrm{~min} ; 94^{\circ} \mathrm{C}$ 变性 $45 \mathrm{~s}, 52^{\circ} \mathrm{C}$ 退火
$45 \mathrm{~s}, 72^{\circ} \mathrm{C}$ 延伸 $45 \mathrm{~s}$, 共 35 个循环; $72^{\circ} \mathrm{C}$ 延伸 $10 \mathrm{~min}$ 。 以上反应均设阴性对照以排除DNA污染的情况。 取 $2 \mu \mathrm{L} \mathrm{PCR}$ 产物进行 1.5\%琼脂糖凝胶电泳 $(U=300$ $\mathrm{V})$, 使用回收试剂盒(上海沃森生物科技公司)对目 的条带进行回收纯化, 使用ABI Prism3730型DNA 序列分析仪对回收纯化的PCR产物进行正反链测 序。将测得的COI基因片段序列用DNAStar软件中 的 Seqman 软件进行比对, 并辅以人工校正。从 GenBank中下载地中海史密斯氏银口天竺鲖和其他 银口天竺鲷属鱼类、黑似天竺鲖(Apogonichthyoides niger)、犬牙拟天箨鲷(Pseudamia gelatinosa)的COI基 因片段(表1)与本研究测定的Jaydia sp.序列进行联合 分析。使用MEGA6.0软件以邻接(NJ)法构建系统发 育树, 并计算组群间和组群内的成对Kimura双参数 (K2P)遗传距离。

\section{2 结果}

\section{1 银口天答鲷属的描述}

\section{银口天竺鲷属 (Jaydia Smith, 1961)}

Jaydia Smith, 1961, 375, 392; 模式种: Apogon ellioti Day, 1875, 为Jaydia truncata (Bleeker, 1854) 次定同种异名。

属的特征: 第一背鯺第四鯺棘最长, 前鳃盖骨 边缘锯齿退化, 尾神经骨退化或缺失, 部分种类具

表1 本研究使用序列信息

Table 1 Information of sequences used in this study

\begin{tabular}{|c|c|c|c|}
\hline 种类 & 凭证标本 & 采集地点 & GenBank序列号 \\
\hline Species & Voucher specimens & Locality & GenBank accession no. \\
\hline \multirow[t]{4}{*}{ Jaydia sp. } & OUC_FEL AP150553 & 中国海南西北海域 Northwest Hainan, China & MH638643 \\
\hline & OUC_FEL AP150620 & 中国广东珠海 Zhuhai, Guangdong, China & MH638648 \\
\hline & OUC_FEL AP150622-150625 & 中国广东珠海 Zhuhai, Guangdong, China & MH638644-MH638647 \\
\hline & OUC_FEL AP150858 & 中国浙江舟山 Zhoushan, Zhejiang, China & KX388253 \\
\hline \multirow[t]{2}{*}{ 史密斯氏银口天竺鲷 Jaydia smithi } & AUBM Lot 05-06 & 地中海 Mediterranean Sea & KR861532-KR861533 \\
\hline & ApSm22A-C, G-X & 以色列 Israel & KM538174-KM538194 \\
\hline 黑边银口天竺鲷 Jaydia truncata & FAKU: 73386 & 日本高知 Kochi, Japan & AB890050 \\
\hline 印度洋银口天竺鲷 Jaydia striatodes & ZMNH AF0000118 & 中国广西北海 Beihai, Guangxi, China & KU507413 \\
\hline 横带银口天竺鲷 Jaydia striata & KAUM-I. 47748 & 泰国罗勇 Rayong, Thailand & KU865174 \\
\hline 斑鳍银口天竺鲷 Jaydia carinata & FAKU: 73706 & 日本高知 Kochi, Japan & AB890049 \\
\hline 奎氏银口天竺鲷 Jaydia queketti & TAU P.15450 & 以色列 Israel & KF564297 \\
\hline 细条银口天竺鲖 Jaydia lineata & FAKU: 77532 & 日本广岛 Hiroshima, Japan & AB890051 \\
\hline 新几内亚银口天笂鲷 Jaydia novaeguineae & SAIAB 96303 & 肯尼亚 Kenya & KX281185 \\
\hline 黑似天竺鲖 Apogonichthyoides niger & FAKU: 70753 & 日本爱媛 Ehime-ken, Japan & AB890026 \\
\hline 犬牙拟天竺鲷 Pseudamia gelatinosa & KU: 31854 & 斐济瓦努阿莱武岛 Vanua Levu, Fiji & AB890005 \\
\hline
\end{tabular}




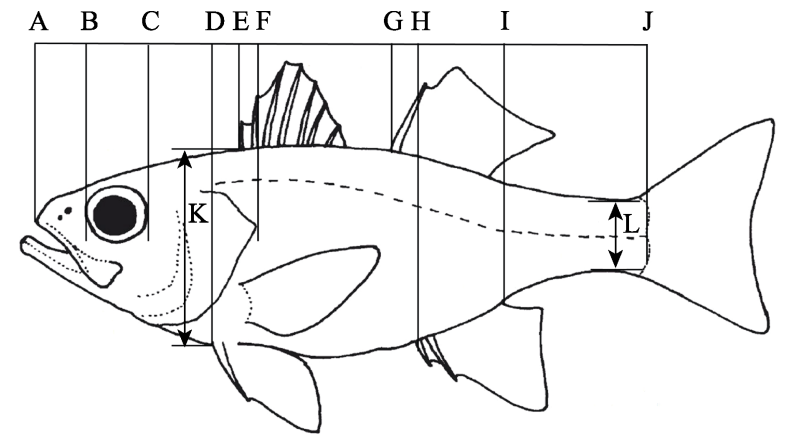

图1 形态测量示意图。A-B: 吻长; B-C: 眼径; A-D: 吻到腹 鯺起点; A-E: 吻到第一背鯺起点; A-F: 头长; A-G: 吻到第 二背鯺起点; A-H: 吻到慰鯺起点; A-I: 体长; I-J: 尾柄长, $\mathbf{K}$ : 体高, L: 尾柄高。

Fig. 1 Methods of measurements. AB, Snout length; B-C, Eye diameter; A-D, Snout to origin of pelvic fin; $\mathrm{AE}$, Snout to origin of first dorsal fin; A-F, Head length; AG, Snout to second dorsal fin; A-H, Snout to origin of anal finl, A Standard length; FJ, Caudal peduncle length; K, Body depth; $\mathrm{L}$, Caudal peduncle depth.

有发光器官; 背鯺鯺条数VII + I, 9, 臀鯺鯺条数II, 8, 胸鳍鯺条数14-18 (通常为15-17), 腹鳍鳍条数I, 5, 尾鯺鯺条数 $9+8$; 侧线鳞数 $24+3-4$ (通常为 3 ), 侧 线上鳞数 2 , 侧线下鳞数 6 ; 背前鳞数 $2-5$; 鳃耙数 $13-$ 19 , 发达鳃耙数10-15, 角鳃耙数8-9; 尾鯺通常为圆 形; 体侧通常具有4-12横带; 第一背鯺上端通常微 黑到黑色。

\section{2 中国银口天竺鲖属各物种鉴别特征和分布}

种类鉴定主要根据Gon (1997)进行。仅列出与 中国记录相关的异名。对物种分布范围的重新阐 述综合了本研究和已有可信记录。检视的标本、

异名录、形态特征描述和分类讨论见附录2。

\subsection{1 斑鯺银口天筷鲷 Jaydia carinata Cuvier in} Cuvier \& Valenciennes, 1828 (图2A, B, 附录3-表A3)

鉴别特征: 胸鳀鯺条数16-17 (通常为16); 总鳃 耙数3-4 + 11-13 = 14-16, 发达鳃耙数 $1+9-11=10-$ 12 , 角鳃耙数 $8-9$ (通常为8); 背前鳞数 $2-3$ (通常为 3 ); 前鳃盖骨边缘光滑, 前鳃盖骨脊边缘光滑; 第二背鯺 后4枚鯺条于基部上方具一大黑斑, 黑斑外圈白色。

世界分布: 西太平洋, 日本、韩国、中国、菲 律宾及澳大利亚北部(Gon, 1997; Kim et al, 2005); 中国分布: 黄海南端(偶见)、东海、台湾及南海(成 庆泰等, 1962; 成庆泰, 1963; 沈根媛, 1985; 沈世杰, 1993; 刘培廷和邓思明, 2006)。

\subsection{2 细条银口天筷鲷 Jaydia lineata Temminck \&} Schlegel, 1842 (图2C, 附录3-表A3)

鉴别特征: 胸鯺鯺条数14-16 (通常为15); 总鳃 耙数2-5 + 11-14 = 15-19 (通常为3-4 + 12-13 = 1618), 发达鳃耙数 $1-3+11-13=13-15$ (通常为 $2+11-$ $12=13-14$ ), 角鳃耙数8-9 (通常为9); 背前鳞数3-4; 前鳃盖骨边缘具弱锯齿, 前鳃盖骨脊边缘光滑; 体侧 具7-12棕色窄横带, 带宽通常小于带间距。

世界分布: 西北太平洋, 包括日本、韩国、中 国海域(Gon, 1997; Kim et al, 2005); 中国分布: 黄渤 海、东海、台湾(沈世杰, 1993; 沈世杰和吴高逸, 2011)及南海北部。

\subsection{3 新几内亚银口天筷鲷 Jaydia novaeguineae} Valenciennes 1832 (图2D, 附录3-表A3)。

鉴别特征: 胸鳍鯺条数16-17 (通常为16); 总鳃耙 数 $4+11=15$, 发达鳃耙数 $2+11=13$, 角鳃耙数 8 ; 背 前鳞数4-5; 前鳃盖骨边缘具弱锯齿, 前鳃盖骨脊边缘 光滑; 体侧无横带, 或具多达 8 条模糊棕色横带。

世界分布: 印度洋到西太平洋, 中国、日本、 菲律宾、印度尼西亚、泰国湾、印度, 往西到非洲 东部的马达加斯加和肯尼亚(Gon, 1997); 中国分布: 台湾(Gon, 1997)及南海。

\subsection{4 黑鳃银口天竺鲷 Jaydia poeciloptera Cuvier} in Cuvier \& Valenciennes, 1828 (图2E, F, 附录3-表A3)

鉴别特征: 胸鯺鯺条数 15-17 (通常为 16 ); 总鳃 耙数2-4 + 11-12 = 13-16 (通常为3-4 + 11-12 = 1416), 发达鳃耙数 $1+9-11=10-12$ (通常为 $1+10$ ), 角鳃耙数 8 ; 背前鳞数 $4-5$; 前鳃盖骨边缘光滑, 前鳃 盖骨脊边缘光滑; 鳃腔、第一鳃弓及其鳃耙黑色; 上下领近联合处齿明显膨大; 慰鯺近基部具一暗色 纵纹。

世界分布: 广泛分布于印度洋到西太平洋, 从 印度往东到菲律宾, 南到澳大利亚北部, 北到日本 南部海域 (Gon, 1997; Matsunuma et al, 2011; Yoshida et al, 2013); 中国分布: 南海。

\subsubsection{Jaydia sp. (图2G, 附录3-表A3)}

鉴别特征: 胸鳍鯺条数 16-17; 总鳃耙数 $2-4+$ 11-12 = 13-16 (通常为3-4 + 11-12 = 14-16), 发达 鳃耙数 $1+9-11=10-12$ (通常为 $1+10$ ), 角鳃耙数 8 ; 前鳃盖骨边缘锯齿状, 前鳃盖骨脊边缘转折处具锯 齿; 头顶部无显眼的暗色斑点; 臀鯺无纵纹。

分布: 中国东海和南海北部, 原在西太平洋记 

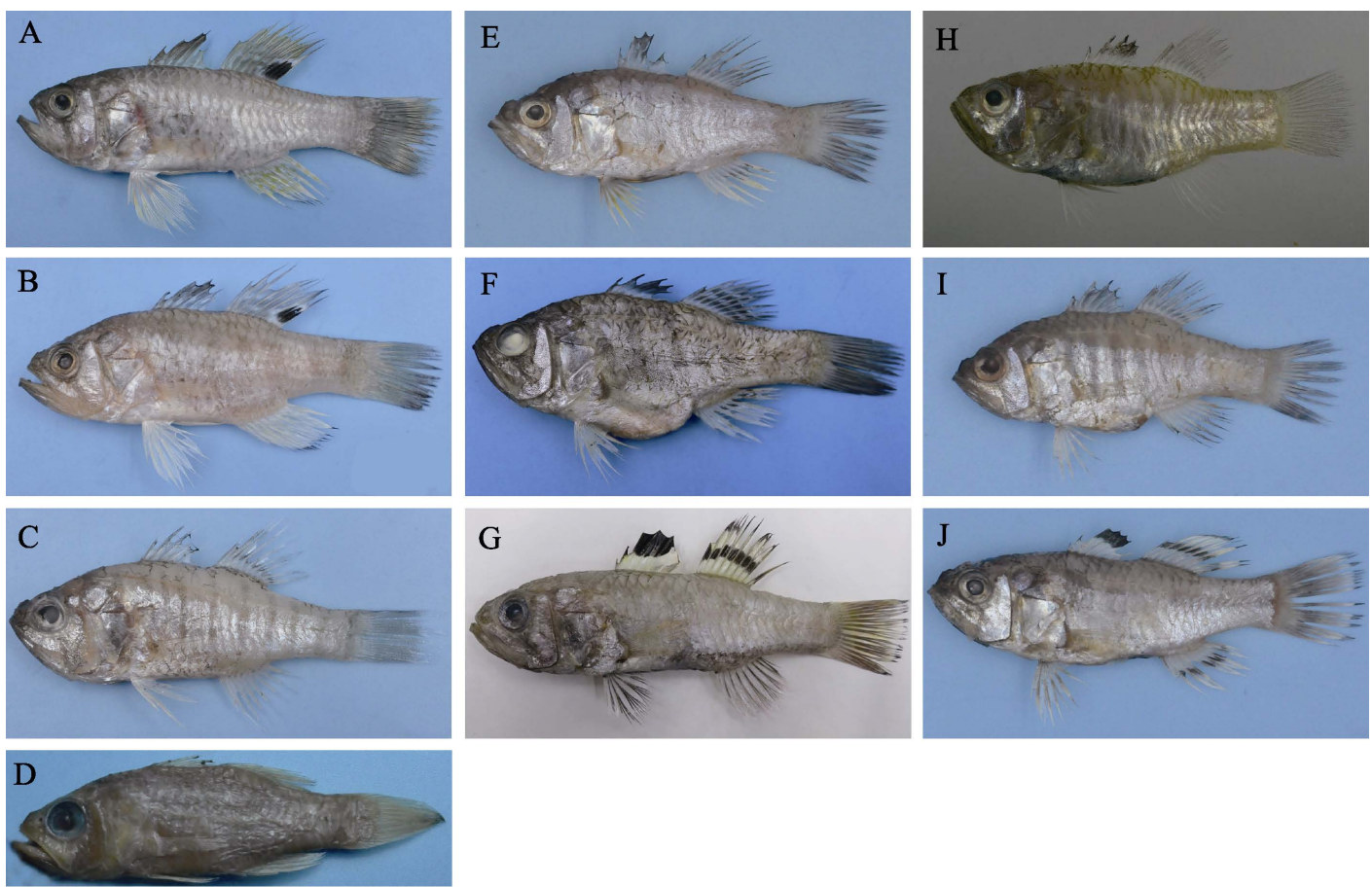

图2 A, B: 斑鯺银口天竺鲷, A: OUC_FEL AP160051, $117.9 \mathrm{~mm}$, 广东珠海, B: OUC_FEL AP140025, 88.8 mm, 广东珠海; C: 细条银口天竺鲷, OUC_FEL AP150819, $57.8 \mathrm{~mm}$, 山东乳山; D: 新几内亚银口天竺鲷, $61.3 \mathrm{~mm}$, 海南三亚, 该标本经福尔马林 溶液保存过, 原有的外部颜色特征已消失; E-F: 黑鳃银口天矢鲷, E: OUC_FEL AP150783, 87.8 mm, 广西北海, F: OUC_FEL AP150782, $68.3 \mathrm{~mm}$, 广西北海; G: Jaydia sp., OUC_FEL AP150625, 98.6 mm, 广东珠海; H: 横带银口天笛鲷, KAUM-I. 47748, $53.2 \mathrm{~mm}$, 泰国罗勇(照片由本村浩之提供); I: 印度洋银口天竺鲷, ZMNH AF0000119, $57.3 \mathrm{~mm}$, 北部湾; J: 黑边银口天 尔鲷, OUC_FEL AP150768, $89.9 \mathrm{~mm}$, 广西北海。

Fig. 2 A, Jaydia carinata, OUC_FEL AP160051, 117.9 mm, from Zhuhai, Guangdong; China, B, J. carinata, OUC_FEL AP140025, 88.8 mm, from Zhuhai, Guangdong; C, J. lineata, OUC_FEL AP150819, 57.8 mm, from Rushan, Shandong; D, J. novaeguineae, $61.3 \mathrm{~mm}$, from Sanya, Hainan Island, the specimen lost its color as it was ever preversed in formalin solution; E, $J$. poeciloptera, OUC_FEL AP150783, 87.8 mm, from Beihai, Guangxi; F, J. poeciloptera, OUC_FEL AP150783, 68.3 mm; from Beihai, Guangxi; G, Jaydia sp., OUC_FEL AP150625, 98.6 mm, from Zhuhai, Guangdong; H: J. striata, KAUM-I. 47748, 53.2 mm, from Ryoung, Thailand (Provided by Hiroyuki Motomura); I, J. striatodes, ZMNH AF0000119, 57.3 mm, the Beibu Gulf; J, J. truncata, OUC_FEL AP150768, 89.9 mm, Beihai, Guangxi.

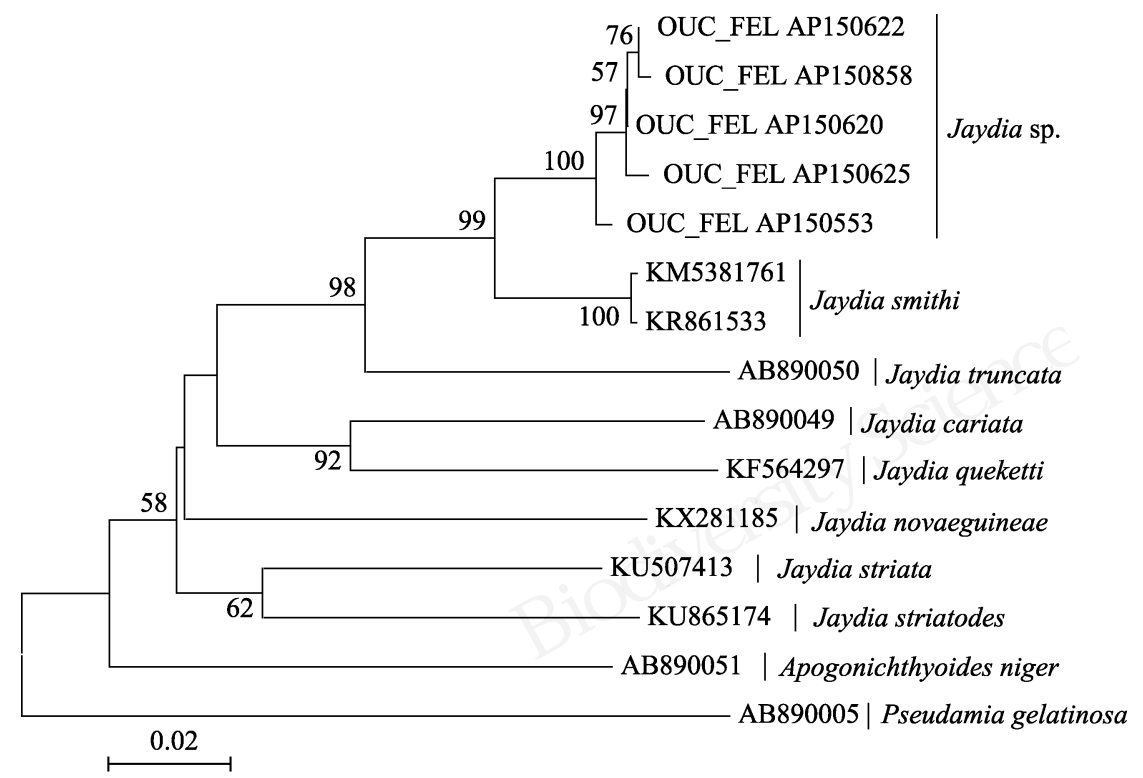

图3 使用COI基因片段基于邻接法构建的银口天矢鲷属系统发育树

Fig. 3 Phylogenetic tree of Jaydia species based on neighbor-joining method using COI sequences 
录的史密斯氏银口天筸鲷应为该种。

本研究使用DNA条形码序列进行遗传学分析, 计算Jaydia sp. 与史密斯氏银口天笙鲷种群间与种 群内遗传距离, 结果显示两者遗传距离为 0.044 , 远 大于两种群组内遗传距离, 也远远大于一般的鱼类 种内遗传距离, 为种间差异水平(附录2-表A2)。以 黑似天竺鲷和犬牙拟天䇥鲷为外群, 使用DNA条形 码序列重建银口天䇥鲖属系统发育树, 结果显示史 密斯氏银口天答鲷中国种群和地中海种群都为具 有排他性的世系, 两者形成姐妹群关系, 且与其他 银口天竺鲖属鱼类明显分开(图3)。

\subsection{6 横带银口天年鲷 Jaydia striata (Smith \&} Radcliffe in Radcliffe, 1912) (图2H, 附录3-表A3)

鉴别特征: 胸鳍鯺条数通常为 15 ; 背前鳞数 $3-5$; 发达鳃耙数通常为 $2+11$; 前鳃盖骨边缘具弱锯齿, 前鳃盖骨脊边缘光滑; 体侧具7-11暗色窄横带; 臀 鯺浅色, 大型个体 $(>60 \mathrm{~mm})$ 在慰鯺下具黑色素分布; 覆膜覆盖有暗色斑点。

世界分布: 印度洋到西太平洋; 中国分布: 台湾 和海南。

\subsection{7 印度洋银口天竺鲷 Jaydia striatodes (Gon, 1997) (图2I, 附录3-表A3)}

鉴别特征: 胸鯺鰙条数 15 ; 总鳃耙数 $4-5+12-13$, 发达鳃耙数 $3+11-12$, 角鳃耙数 9 ; 背前鳞数 4 ; 前鳃 盖骨边缘具弱锯齿, 前鳃盖骨脊边缘光滑; 体侧通常 具8-10条暗色窄横带; 臀鯺下端具黑色素分布。

世界分布: 东印度洋到西北太平洋; 中国分布: 台湾、南海(香港、北部湾)。

\subsection{8 烟台银口天竺鲷 Jaydia tchefouensis (Fang,} 1942), 可能为细条银口天年鲷次定同种异名。

分布: 中国山东烟台。

\subsection{9 黑边银口天竺鲷 Jaydia truncata (Bleeker, 1854) (图2J, 附录3-表A3)。}

鉴别特征: 胸鯺鯺条数16-18 (通常为17); 总鳃 耙数3-4 + 11-13 = 14-17, 发达鳃耙数 $1+9-11=$ 10-12, 角鳃耙数8-9 (通常为8); 背前鳞数3-4 (通常 为4); 前鳃盖骨边缘锯齿状, 前鳃盖骨脊边缘转折处 具锯齿; 头顶部具显著暗色斑点; 第二背鯺和尾鯺 边缘黑色, 第二背鯺和臀鯺中部各具一黑色纵纹。

世界分布：印度洋到西太平洋; 中国分布：东 海、台湾和南海。

\section{3 中国银口天笛鲖属鱼类检索表}

基于详实的形态学比较分析, 我们编制了中国 银口天竺鲷属鱼类的检索表。

1(4)前鳃盖骨边缘光滑无锯齿

2(3)第二背鯺后部具一大黑斑; 鳃腔黑色或浅色, 如黑色, 则上鳃弓及上鳃耙也为黑色; 上下领联合牙齿处轻 微膨大 斑鯺银口天竺鲷(Jaydia carinata)

3(2)第二背鳍具1-3黑色纵纹; 鳃腔、鳃耙和鳃弓黑色; 上下领联合处牙齿明显膨大 黑鳃银口天竺鲷(Jaydia poeciloptera)

4(1)前鳃盖骨边缘具锯齿

$5(12)$ 发达上鳃耙数2-3; 体侧通常具7-12窄横带

6(9)腹膜无黑色素分布, 或零星地点缀着微小黑点

$7(8)$ 胸鯺鯺条数通常为 16 ; 发达鳃耙数9-10; 角鳃耙数通常为8

·新几内亚银口天竺鲷(Jaydia novaeguineae)

$8(7)$ 胸鯺鯺条数通常为 15 ; 发达鳃耙数 $11-12$; 角鳃耙数通常为 9 . 细条银口天竺鲷(Jaydia lineata) 9(6)腹膜具大量黑色素分布

10(11)发达上鳃耙数通常为3; 角鳃耙数通常为 9 ; 臀鯺下部具一宽的黑色素带

.印度洋银口天竺鲖(Jaydia striatodes) 11(10)发达上鳃耙数通常为2; 角鳃耙数通常为8; 臀鯺下部通常无黑色素分布

.横带银口天竺鲷(Jaydia striata)

12(5)发达上鳃耙数 1 ; 体侧通常具4-6宽横带

13(14)头顶具许多显著的黑色斑点; 臀鯺中部具一黑色纵纹. 黑边银口天竺鲷(Jaydia truncata) 14 (13)头顶无显著斑点; 慰鳍中部无纵纹 Jaydia sp. 
表2 中国银口天矢鲷鱼类原记录命名种及其当前状态

Table 2 Nominal species of genus Jaydia recorded from China with their current status

\begin{tabular}{|c|c|}
\hline 命名种 Species & 当前状态 Current status \\
\hline J. albomarginata (Smith \& Radcliffe in Radcliffe 1912) & $\begin{array}{l}\text { 无效, 为新几内亚银口天竺鲖(J.novaeguineae)次定同种异名 } \\
\text { A junior synonym of J. novaeguineae }\end{array}$ \\
\hline J. arafurae (Günther 1880) & $\begin{array}{l}\text { 无效, 中国之记录为黑鳃银口天竺鲷(J. poeciloptera)误鉴 } \\
\text { Misidentification of J.poeciloptera }\end{array}$ \\
\hline J. carinata (Cuvier in Cuvier \& Valenciennes 1828) & 有效 Valid \\
\hline J. ellioti (Day 1875) & 无效, 为黑边银口天竺鲷 (J. truncata) 次定同种异名 A junior synonym of J. truncata \\
\hline J. lineata (Temminck \& Schlege 1842) & 有效 Valid \\
\hline J. novaeguineae (Valenciennes 1832) & 有效 Valid \\
\hline J. poeciloptera (Cuvier in Cuvier \& Valenciennes 1828) & 有效 Valid \\
\hline J. smithi Kotthaus 1970 & 推测为Jaydia sp. May be Jaydia sp. \\
\hline J. striata (Smith \& Radcliffe in Radcliffe 1912) & 有效 Valid \\
\hline J. striatodes (Gon 1997) & 有效, 曾误鉴为横带银口天竺鲷 Valid, but misidentified as $J$. striata \\
\hline J. tchefouensis (Fang 1942) & $\begin{array}{l}\text { 分类地位存疑,可能为细条银口天竺鲷 }(J . \text { lineata)同种异名 } \\
\text { Questionable, may be a junior synonym of J. lineata }\end{array}$ \\
\hline J. truncata (Bleeker 1854) & 有效 Valid \\
\hline
\end{tabular}

\section{3 中国银口天答鲖鱼类分类修订}

\section{1 属名的更正}

Smith (1961)从西印度洋命名了银口天竺鲷属 Jaydia。Fraser (1972)基于比较骨学研究将Jaydia作 为天竺鲷属Apogon的异名。Gon (1997)认为Jaydia 为 Apogon一个有效亚属。Mabuchi 等 (2014) 将 Jaydia提升为属。中国学者原使用属名Apogon和 Apogonichthys应更正为Jaydia。

\section{2 种的修订}

中国记录的银口天竺鲖鱼类存在较多鉴定错 误和学名误用(表2)。其中, Jaydia arafurae (成庆泰 等, 1962; 成庆泰, 1987; 陈大刚和张美昭, 2016)应为 J. poeciloptera; 成庆泰等(1962)报道的横带银口天 竺鲖 $(J$. striata)部分标本实为印度洋银口天竺鲖 $(J$. striatodes); 沈世杰(1993)记载的黑边银口天竺鲖 $(J$. truncata)应为Jaydia sp.。命名种ellioti和arafurae 为 truncata的次定同种异名; 命名种albomarginata为 novaeguineae的次定同种异名。烟台银口天竺鲷可 能为细条银口天䇥鲖次定同种异名, 该种分类地位 尚需依据载名模式标本和后续采样结果进一步确 认。Gon (1997)鉴定的史密斯氏银口天竺鲷包含两 个形态相似但遗传差异明显的物种, 中国群体为一 隐存种Jaydia sp.。

致谢：感谢南非水生生物研究所 (South African Institute for Aquatic Biodiversity)的Ofer Gon和佛罗
里达大学(University of Florida)的Thomas H. Fraser 博士给与的指导和帮助, 感谢中国科学院海洋研 究所的李新正研究员、南海海洋研究所的孔晓瑜 研究员、浙江海洋大学的水柏年教授和韩志强教 授在检视样品过程中给予的支持和帮助, 感谢中 国水产科学院南海水产研究所的孙典荣研究员、 中国科学院南海海洋研究所的孔晓瑜研究员、中 国海洋大学的单斌斌、肖家光、高兵兵等研究 生、北海市水产技术推广站邹建伟副站长、海南 大学的章翔副教授、广东海洋大学的李忠炉老 师、大连市水产研究所的问龙先生、自然资源部 第三海洋研究所的钟指挥先生和浙江海洋水产研 究所的各位同仁帮助采集中国银口天筑鲖属鱼类 样品，感谢新加坡李光前自然历史博物馆(Lee Kong Chian Natural History Museum)的Kelvin K P Lim帮助检视了相关馆藏标本。

\section{ORCID}

俞正森 (D) https://orcid.org/0000-0002-8381-2025

\section{参考文献}

Bleeker P (1849) Bijdrage tot de kennis der Percoïden van den Malaijo-Molukschen Archipel, met beschrijving van 22 nieuwesoorten. Verhandelingen Bataviaasch Genootschap, 22(4), 1-64.

Bleeker P (1854) Bijdrage tot de kennis der ichthyologische fauna van het eiland Floris. Natuurkundig Tijdschrift voor Nederlandsch Indië, 6, 311-338. 
Chen DG, Zhang MZ (2016) Marine Fishes of China, pp. 10101059. China Ocean University Press, Qingdao. (in Chinese) [陈大刚, 张美昭 (2016) 中国海洋鱼类, 1010-1059页. 中 国海洋大学出版社, 青岛.]

Cheng QT (1959a) Illustration of Chinese Animals (Fish, Volume 4), pp. 14-18. Science Press, Beijing. (in Chinese) [成庆泰 (1959a) 中国动物图谱(鱼类第4册), 14-18页. 科 学出版社, 北京.]

Cheng QT (1959b) A checklist of the cardinalfishes (Percomorpha: Apogonidae) in China and new records. Chinese Journal of Zoology, 8, 359-362. (in Chinese) [成庆 泰 (2015) 我国的天筸鲖科鱼类及其新纪录. 动物学杂志, 8, 359-362.]

Cheng QT, Wang CX, Tian MC, Yang WH, Sun BL (1962) Family Apogonidae. In: Fishes in the South China Sea (eds Zhu YD, Zhang CL, Zhang YW et al), pp. 328-347. Science Press, Beijing. (in Chinese) [成庆泰, 王存信, 田明诚, 杨文 华, 孙宝龄 (1962). 天竺鲖科. 见: 南海鱼类志(朱元鼎, 张 春霖, 张有为等主编), 328-347页. 科学出版社, 北京.]

Cheng QT (1963) Family Apogonidae. In: Fishes in the East China Sea (eds Zhu YD, Zhang CL, Cheng QT), pp. 233238. Science Press, Beijing. (in Chinese) [成庆泰 (1963) 天 竺鲷科. 见: 东海鱼类志 (朱元鼎, 张春霖, 成庆泰主编), 233-238页. 科学出版社, 北京.]

Cheng QT (1987) Family Apogonidae. In: Systematic Synopsis of Chinese Fishes (eds Cheng QT, Zheng BS), pp. 300-303. Science Press, Beijing. (in Chinese) [成庆泰 (1987) 天矢鲷 科. 见: 中国鱼类系统检索(成庆泰, 郑葆珊主编), 300-303 页. 科学出版社, 北京.]

Cuvier G (1828) Des apogons. In: Histoire naturelle des poisons, 2 (eds Cuvier G, Valenciennes A), pp. 145-160. F.G. Levrault, Paris.

Fang PW (1942) Poissons de Chine de M. Ho: Description de cinqespècesetdeux sous-espècesnouvelles. Bulletin de la Société Zoologique de France, 67, 79-85.

Fraser TH (1972) Comparative osteology of the shallow water cardinal fishes (Perciformes: Apogonidae) with reference to the systematics and evolution of the family. Ichthyological Bulletin of the J. L. B. Smith Institute of Ichthyology, 34, 1105.

Fraser TH (2011) A new cardinalfish of the genus Apogonichthyoides (Perciformes, Apogonidae) from Raja Ampat Islands, with a key to species. Zootaxa, 3095, 63-68.

Fraser TH (2014) Foa yamba, a new species of cardinalfish (Percomorpha: Apogonidae: Apogonichthyini) from the tidal region of the Clarence River, Australia and redescriptions of the West Pacific Foalongimana and Foahyalina. Zootaxa, 3878, 167-178.

Fraser TH, Prokofiev AM (2016) A new genus and species of cardinalfish (Percomorpha, Apogonidae, Sphaeramiini) from the coastal waters of Vietnam: luminescent or not? Zootaxa, 4144, 227-242.

Fricke R, Eschmeyer WN, Van der Laan R (2020a)
Eschmeyer's catalog of fishes: Genera, species, references. http://researcharchive.calacademy.org/research/ichthyology/ catalog/fishcatmain.asp. (accessed on 2020-06-22)

Fricke R, Eschmeyer WN, Fong JD (2020b) Eschmeyer's catalog of fishes: Genera/species by family/subfamily. https://researcharchive.calacademy.org/research/ichthyology/ catalog/SpeciesByFamily.asp. (accessed on 2020-06-22)

Gon O (1997) Revision of the cardinalfish subgenus Jaydia (Perciformes, Apogonidae, Apogon). Transactions of the Royal Society of South Africa, 51, 147-194.

Gon O, Liao YC, Shao KT (2015) A new species of the cardinalfish genus Jaydia (Teleostei: Apogonidae) from the Philippines. Zootaxa, 3980, 286-292.

Kim IS, Choi Y, Lee CL, Lee YJ, Kim BJ, Kim JH (2005) Illustrated Book of Korean Fishes. Kyo-Hak Publishing Co., Seoul.

Liu PT, Deng SM (2006) Family Apogonidae. In: Fishes of Jiangsu Province (eds Ni Y, Wu HL), pp. 501-504. China Agriculture Press, Beijing. (in Chinese) [刘培廷, 邓思明 (2006) 天竺鲷科. 见: 江苏鱼类志(倪勇, 伍汉霖主编), 501-504页. 中国农业出版社, 北京.]

Mabuchi K, Fraser TH, Song H, Azuma Y, Nishida M (2014) Revision of the systematics of the cardinalfishes (Percomorpha: Apogonidae) based on molecular analyses and comparative reevaluation of morphological characters. Zootaxa, 3846, 151-203.

Matsunuma M, Motomura H, Matsuura K, Shazili NAM, Ambak MA (2011) Family Apogonidae. In: Fishes of Terengganu: East Coast of Malay Peninsula, Malaysia (eds Matsunuma M, Motomura H, Matsuura K, Shazili NAM, Ambak MA), pp. 87-93. National Museum of Nature and Science, Tokyo, Universiti Malaysia Terengganu, Terengganu, Kagoshima University Museum, Kagoshima.

Nelson JS (2006) Fishes of the World, 4th edn. John Wiley \& Sons, Hoboken.

Shen GY (1985) Family Apogonidae. In: The Fishes of Fujian Province (Part II) (ed. Zhu YD), pp 45-57. Fujian Science and Technology Press, Fujian. (in Chinese) [沈根媛 (1985) 天矢鲷科. 见: 福建鱼类志下卷(朱元鼎主编), 45-57页. 福 建科学技术出版社, 福州.]

Shen SJ (1993) Fishes of Taiwan pp. 308-323. Department of Animal Science and Technology, Taiwan University, Taibei. (in Chinese) [沈世杰 (1993) 台湾鱼类志, 308-323页. 台湾 大学动物学系, 台北.]

Shen SJ, Wu GY (2011) Fishes of Taiwan, pp. 397-416. Museum of Marine Biology \& Aquarium, Pingdong. (in Chinese) [沈世杰, 吴高逸 (2011) 台湾鱼类图鉴, 397-416 页. 海洋生物博物馆, 屏东.]

Smith JLB (1961) Fishes of the family Apogonidae of the western Indian Ocean and the Red Sea. Ichthyological Bulletin, Department of Ichthyology, Rhodes University, 22, 373-418, Pls. 46-52.

Smith M, Radcliffe L (1912) Amia striata and Amia 
albomarginata. In: Descriptions of fifteen new fishes of the family Cheilodipteridae, from the Philippine Islands and contiguous waters (ed. Radcliffe L), pp. 437-438. Proceedings of the United States National Museum, 41, 431-446, Pls. 34-38.

Sun DR, Chen Z (2013) Synopsis of Fishes in the South China Sea, pp. 450-468. China Ocean Press, Beijing. (in Chinese) [孙典荣, 陈铮 (2013) 南海鱼类检索, 450-468页. 海洋出 版社, 北京.]

Thacker CE (2009) Phylogeny of Gobioidei and placement within Acanthomorpha, with a new classification and investigation of diversification and character evolution. Copeia, 1, 93-104.

Thacker CE, Roje DM (2009) Phylogeny of cardinalfishes (Teleostei: Gobiiformes: Apogonidae) and the evolution of visceral bioluminescence. Molecular Phylogenetics and Evolution, 52, 735-745.

Thacker CE, Satoh TP, Katayama E, Harrington RC, Eytan RI, Near TJ (2015) Molecular phylogeny of Percomorpha resolves Trichonotus as the sister lineage to Gobioidei
(Teleostei: Gobiiformes) and confirms the polyphyly of Trachinoidei. Molecular Phylogenetics and Evolution, 93, 172-179.

Wang YK (1958) Taxonomy of Fishes, pp. 290-294. Shanghai Scientific \& Technical Publishers, Shanghai. (in Chinese) [王以康 (1958) 鱼类分类学, 290-294页. 上海科学技术出 版社, 上海.]

Ward RD, Zemlak TS, Innes BH, Last PR, Hebert PDN (2005) DNA barcoding Australia's fish species. Philosophical Transactions of the Royal Society of London B: Biological Sciences, 360, 1847-1857.

Yoshida T, Motomura H, Musikasinthorn P, Matsuura K (2013) Fishes of Northern Gulf of Thailand, pp. 105-110. National Museum of Nature and Science, Tsukuba, Research Institute for Humanity and Nature, Kyoto, and Kagoshima University Museum, Kagoshima.

(责任编委: 何舜平 责任编辑: 周玉荣)

\section{附录 Supplementary Material}

\section{附录1 形态学测量和计数方法}

Appendix 1 Methods of morphological measurements and counts https://www.biodiversity-science.net/fileup/PDF/2020320-1.pdf

附录2 各物种标本信息、异名录、形态特征描述和分类讨论

Appendix 2 Materials examined, synonyms, morphological description and remarks https://www.biodiversity-science.net/fileup/PDF/2020320-2.pdf

\section{附录3 中国银口天竺鲷属鱼类主要形态特征差异分析}

Appendix 3 Morphological comparison of Jaydia species in China https://www.biodiversity-science.net/fileup/PDF/2020320-3.pdf 
俞正森, 宋娜, 本村浩之, 高天翔 (2021) 中国银口天竺鲷属鱼类的分类厘定. 生物多样性, 29, 971-979. http://www.biodiversityscience.net/CN/10.17520/biods.2020320

附录 1 形态学测量和计数方法

Appendix 1 Methods of morphological measurements and counts

上领长(upper jaw length): 上领前端到末端的距离。

下领长(lower jaw length): 下领前端到末端的距离。

眼间距(interorbital width): 两眼背缘骨骼之间的最短距离。

软条或鯺棘长(length of ray or spine): 基部到软条或鰙棘末端的距离。

胸鯺长(length of pectoral fin): 胸鯺基部上前端到最长胸鯺鰙条末端的距离。

腹鯺长(length of pelvic fin): 腹鯺基部上前端到最长腹鯺鯺条末端的距离。

肛门到慰鯺起点(anus to origin of anal fin): 肛门后缘到臂鯺起点的距离。

胸鯺鯺条数(pectoral-fin rays): 计数所有胸鯺鯺条, 包括最上和最下两枚不发达的不分枝鯺条。

背鯺鯺条数(dorsal-fin rays): 分为三部分, 第一背鳍鯺棘数 + 第二背鳍鳍棘数 + 第二背鯺软条数, 由一枚支 鯺骨支撑从基部即分支的软条计为 1 枚软条。

臂鯺鯺条数(anal-fin rays): 分为两部分, 慰鯺鯺棘数 + 臂鯺软条数, 由一枚支鰙骨支撑从基部即分支的软条 计为 1 枚软条。

腹鯺鯺条数(pelvic-fin rays): 分为两部分, 腹鯺鯺棘数 + 腹鯺软条数。

尾鰙鯺条数(caudal-fin rays): 分为两部分, 尾鯺上叶鯺条数 + 下叶鯺条数, 包含所有分支鯺条及上叶和下叶 与分支鯺条相邻的各一枚不分支鯺条。

侧线鳞(lateral line scales): 用两部分给出, 后题骨到尾下骨板末端的有孔鳞数 + 其后的有孔鳞数。

侧线上(下)鳞(transverse scale rows): 从第一背鯺(慰鯺)起点向后下方(上前方)计数, 到侧线鳞为止所得的鳞 列数, 但不包括侧线鳞。

背前鳞(predorsal scales): 从项部到第一背鯺起点之间正中线上的一列鳞片的数量。

鳃耙数(gill rakers): 计数左侧第一鳃弓鳃耙数, 分为上鳃耙(upper gill rakers)和下鳃耙(lower gill rakers)两部 分, 上鳃骨上着生的鳃耙数为上鳃耙数, 角鳃骨和下鳃骨上着生的鳃耙数为下鳃耙数; 角鳃骨上的鳃耙数目 为角鳃耙数(ceratobranchial rakers); 处于角鳃骨与上鳃骨连接处的鳃耙计入下鳃耙数, 处于角鳃骨与上鳃骨 或下鳃骨的连接处的鳃耙均计入角鳃耙数; 所有鳃耙分为发达鳃耙(developed gill rakers)与退化鳃耙 (rudiments)两种, 退化鳃耙为微小的、长与其基部宽大约相等或者更小的鳃耙。 
俞正森, 宋娜, 本村浩之, 高天翔 (2021) 中国银口天竺鲷属鱼类的分类厘定. 生物多样性, 29, 971-979. http://www.biodiversityscience.net/CN/10.17520/biods.2020320

附录2 各物种标本信息、异名录、形态特征描述和分类讨论

Appendix 2 Materials examined, synonyms, morphological description and remarks

\section{1 斑鯺银口天笛鲷}

检视中国标本 61尾，体长39.3-117.9 mm。 SCSIOCAS 0601(该标本瓶中有两尾标本, 其中小的 一尾鉴定为该种, 大的一尾被重新鉴定为黑边银口 天竺鲷), $59.5 \mathrm{~mm}$, 粤东沿海, 1982年 8 月 9 日; OUC_FEL AP150551-150552, 2: 102.4-104.9 mm, 海南岛西北海域, 2014 年 9 月 1 日; OUC_FEL AP150587，101.1 mm，上海，2014年 11 月 9 日; OUC_FEL AP150629-150648, 20: 70.7-110.3 mm, 广东珠海, 2014年11月20日; OUC_FEL AP140022140026, 5: 87.0-101.7 mm, 广东珠海, 2014年12月22 日; OUC_FEL AP150634-150651, 18: 39.3-97.3 mm, 浙江舟山, 2015年10月20日; OUC_FEL AP160051160054, 4: 100.8-117.9 mm, 广东珠海, 2016年1月 13日。

Apogon carinatus Cuvier in Cuvier \& Valenciennes, 1828. Histoire Naturelle des Poisons: 157; 模式产地: 日本; 锯缘天竺鲷, 沈世杰, 1984. 台 湾鱼类检索: 236; 单斑天竺鲷, 沈世杰, 1993. 台湾 鱼类志: 310, 图版80-10; 斑鯺天竺鲷, 刘培廷和邓思 明, 2006. 江苏鱼类志: 502, 图245 (吕四); 斑鳍天竺 鲖, 赵盛龙和钟俊生, 2006. 舟山海域鱼类原色图鉴: 103, 图170; 斑鯺天竺鲷, 刘瑞玉, 2008. 中国海洋生 物名录: 974; 单斑天竺鲷, 沈世杰和吴高逸, 2011. 台湾鱼类图鉴: 398; 斑鯺天竺鲷, 孙典荣和陈铮, 2013. 南海鱼类检索: 457, 图812; 斑鯺天答鲷, 陈大 刚和张美昭, 2016. 中国海洋鱼类: 1048; 斑鯺天竺 鲷, 赖廷和和何斌源, 2016. 广西北部湾海洋硬骨鱼 类图鉴: 156。

Apogonichthys carinatus: 隆线天竺鱼, 王以康, 1958. 鱼类分类学: 292, 图300; 斑鯺拟天竺鲷, 成庆 泰, 1959a, 中国动物图谱 鱼类第四册: 16, 图31; 斑 鯺拟天竺鲷, 成庆泰, 1959b, 动物学杂志, 8: 361; 斑 䱜天答鱼, 成庆泰等, 1962. 南海鱼类志: 337, 图281 (汕尾); 斑鯺天答鱼, 成庆泰, 1963. 东海鱼类志: 234, 图180 (浙江洋鞍); 斑鯺天答鱼, 沈根媛, 1985. 福建 鱼类志(下): 51, 图381 (霞浦三沙外海); 斑䰹天笛鱼, 成庆泰, 1987. 中国鱼类系统检索(上册): 301, 图 1472 。
形态特征描述。背鯺鯺条数VII + I, 9, 臀鯺鯺 条数II, 8, 胸鯺鯺条数16-17 (通常为16); 总鳃耙数 3-4 + 11-13 = 14-16, 发达鳃耙数 $1+9-11=10-12$, 角鳃耙数 8-9 (通常为 8 ); 侧线鳞数 $24+3$, 侧线上 鳞数 2 , 侧线下鳞数 6 , 背前鳞数 $2-3$ (通常为 3 ), 为 圆鳞。

上下领、犁骨、颚骨具细小圆雉状齿, 上下领 联合处齿略微膨大; 脊椎骨数 $10+14$, 具 2 枚上神经 骨, 3枚尾上骨, 5枚游离尾下骨, 2枚尾神经骨; 后题 骨后缘光滑; 眶下骨边缘光滑; 前鳃盖骨边缘光滑 无锯齿(呈波纹状), 大型个体有时于转折处具1-3枚 弱锯齿, 前鳃盖骨脊边缘光滑。体大部分具大型薄 栉鳞, 背前区、㚘部和峡部至喉部具圆鳞。

体色。酒精浸制标本体浅棕色至棕色, 头部背 侧及体背侧面颜色较深, 头部腹侧及体腹侧面颜色 浅; 吻部具黑色素分布, 呈棕色; 项部具一棕色斜纹 自眼下缘延伸至颊部下方; 颢部具一斜向上的棕色 短条纹; 头部腹面无黑色素分布; 鳃腔浅色或黑色, 如为黑色, 则第一鳃弓之上鳃骨也为黑色; 体侧通 常具4-7条模糊的棕色横带(新鲜时有时无)及棕色 斑纹(新鲜时不明显); 第一背鯺上部微黑; 第二背鰙 后4枚鯺条基部上方具一大黑斑, 黑斑外圈白色; 胸 鯺和腹鯺无黑色素分布; 慰鯺边缘黑色; 尾鯺微黑 色, 通常末端颜色稍加深; 胃黑色, 肠及腹膜无黑色 素分布。

新鲜标本体色与以上描述相近, 但体侧之横带 可能不显现, 斑纹有时不明显; 各鯺及体侧具黄色 分布; 慰鯺有时具 2-6黄色纵纹; 胸鳍有时为浅红 色。新鲜标本照片见正文图2A, B及文献记录(沈世 杰, 1993; 赵盛龙和钟俊生, 2006; 陈大刚和张美昭, 2016)。

分类讨论。斑鯺银口天竺鲷属于斑鯺银口天 竺鲖种团。该种团另外包含黑鳃银口天竺鲖 (Jaydia poeciloptera) 和奎氏银口天竺鲷 (Jaydia queketti)。它们具有以下共同特征: 前鳃盖骨边缘 及后题骨后缘光滑、体侧具斑纹(有时连成线条)和 覆膜无黑色素分布。其他种类前鳃盖骨边缘或多 或少具有锯齿, 后畋骨后缘弱锯齿状, 体侧只在侧 线上方具斑纹。奎氏银口天竺鲷仅在地中海 
俞正森, 宋娜, 本村浩之, 高天翔 (2021) 中国银口天竺鲷属鱼类的分类厘定. 生物多样性, 29, 971-979. http://www.biodiversityscience.net/CN/10.17520/biods.2020320

(Eryilmaz \& Dalyan, 2006; Akyol \& Ünal, 2015)及印 度洋有分布(Gon, 1997)。斑鯺银口天竺鲷与黑鳃银 口天竺鲷在中国海域同域分布, 前者通过第二背鯺 后部的大黑斑可与后者轻易区分开。此外, 斑鳍银 口天竺鲷具 2-3枚背前鳞; 鳃腔和第一鳃弓及鳃耙 为浅色, 或鳃腔黑色, 第一鳃弓上鳃骨黑色, 鳃弓其 余部分及鳃耙浅色; 肠浅色。而黑鳃银口天竺鲷具 4-5枚背前鳞; 鳃腔和第一鳃弓及鳃耙黑色; 肠覆盖 有黑色素。

\section{2 细条银口天竺鲷}

检视中国标本107尾, 体长29.5-68.0 mm。未编 号保存标本, 29: 49.1-68.0 mm, 山东胶南, 2014年7 月1日; OUC_FEL AP150572-150579, 8: 29.5-51.8 $\mathrm{mm}$, 山东胶南, 2014 年 10 月 27 日; OUC_FEL AP150588-150608, 21: 48.6-58.4 mm, 上海, 2014年 11月9日; OUC_FEL AP150751-150762, 12: 52.5$63.9 \mathrm{~mm}$, 山东胶南, 2015年6月1日; OUC_FEL AP150763-150767, 5: 54.5-58.7 mm, 山东胶南, 2015年7月7日; OUC_FEL AP150810-150819, 10: 52.8-66.1 mm, 山东乳山，2015 年 8 月 15 日; OUC_FEL AP150850-150857, 8: 53.6-64.2 mm, 浙 江舟山，2015年10月16日; OUC_FEL AP150871150883, 13: 49.6-60.9 mm, 浙江舟山, 2015年10月20 日; IOCAS 03107 (54-0409), $52.2 \mathrm{~mm}$, 广西北海, 1954年10月23日。

其他标本。ZRC (Raffles Museum of Biodiversity Research, Singapore) 53454, 新加坡实 龙岗海港, 李光前自然历史博物馆(Lee Kong Chian Natural History Museum)的Kelvin Kok Peng Lim帮 助查看了该标本。

Apogon lineatus: Temminck \& Schlegel, 1842, Fauna Japonica Part 1: 3, 模式产地: 日本长崎; 天竺 鲷, 成庆泰, 1955. 黄渤海鱼类调查报告: 98; 线天竺 鲖, 王以康, 1958. 鱼类分类学: 293; 横纹天竺鲷, 沈 世杰, 1984. 台湾鱼类检索: 237; 细条纹天竺鲷, 沈 世杰, 1993. 台湾鱼类志: 313, 图版82-10; 细条天竺 鲷, 刘培廷和邓思明, 2006. 江苏鱼类志: 503, 图246 (海州湾、连云港、黄海南部、吕四); 细条天筸鲷, 赵盛龙和钟俊生, 2006. 舟山海域鱼类原色图鉴: 103, 图169; 细条天竺鲖, 刘瑞玉, 2008. 中国海洋生 物名录: 975; 细条纹天竺鲷, 沈世杰和吴高逸, 2011.
台湾鱼类图鉴: 403; 细条天竺鲖, 孙典荣和陈铮, 2013. 南海鱼类检索: 458, 图814; 细条天竺鲖, 刘敏 等, 2013. 中国福建南部海洋鱼类图鉴: 158; 细条天 竺鲷, 陈大刚和张美昭, 2016. 中国海洋鱼类: 1499; 细条天竺鲖, 赵盛龙等, 2016. 浙江海洋鱼类志: 597, 图414。

Apogonichthys lineatus: 细条拟天竺鲷, 成庆泰, 1959a. 中国动物图谱 鱼类(第4册): 15, 图30; 细条拟 天竺鲷, 成庆泰, 1959b. 动物学杂志, 8: 360; 细条天 竺鱼, 成庆泰等, 1962. 南海鱼类志: 333, 图277 (北 海); 细条天筸鱼, 成庆泰, 1963. 东海鱼类志: 233, 图 179 (竹屿、大陈、沈家门、东庠); 细条天筸鱼, 沈 根媛, 1985. 福建鱼类志(下卷): 49, 图379 (福鼎沙 埕、霞浦三沙、平潭苏澳、东庠、东山、三沟渔 场、台湾浅滩、台湾堆以南海域); 细条天䇥鱼, 成 庆泰, 1987. 中国鱼类系统检索: 301, 图1467; 细条 天答鱼, 成庆泰, 1997. 山东鱼类志: 256, 图187; 细 条天答鱼, 黄克勤和许成玉, 1990. 上海鱼类志: 254 , 图141; 细条天竺鱼, 李金平等, 1999. 澳门鱼类: 86; 细条天竺鲖, 徐学军, 2001. 河北动物志(鱼类): 2017, 图143。

形态特征描述。背鯺鯺条数VII + I, 9, 慰鯺鯺 条数II, 8, 胸鯺鯺条数14-16 (通常为15); 总鳃耙数 $2-5+11-14=15-19$ (通常为3-4 + 12-13 = 16-18), 发达鳃耙数 $1-3+11-13=13-15$ (通常为 $2+11-12$ $=13-14$ ), 角鳃耙数8-9 (通常为9); 侧线鳞数 $24+$ 3 , 侧线上鳞数 2 , 侧线下鳞数 6 , 背前鳞数 $3-4$, 为 栉鳞。

上下领、犁骨、颚骨具细小圆锥状齿, 上下领 联合处齿略微膨大; 脊椎骨数 $10+14$, 具3枚上神经 骨、3枚尾上骨、5枚游离尾下骨, 尾神经骨缺失; 后题骨后缘锯齿状; 眭下骨腹缘光滑; 前鳃盖骨边 缘具弱锯齿, 前鳃盖骨脊边缘光滑无锯齿; 体具大 型薄栉鳞, 项部鳞部分为圆鳞。

体色。酒精浸制标本体浅棕色至棕色, 头部背 侧及体背侧面颜色较深, 头部腹侧及体腹侧面颜色 浅; 吻部具黑色素分布, 呈棕色; 颊部具一棕色斜纹; 头部腹面无黑色素分布; 鰓腔和鳃浅色; 体侧具712 (通常为8-10)棕色窄横带, 带宽通常明显小于带 间距; 侧线上方鳞囊末端暗色; 第一背鯺上部微黑 色; 第二背鯺上部具黑色素分布, 末端浅色或微黑, 
俞正森, 宋娜, 本村浩之, 高天翔 (2021) 中国银口天竺鲷属鱼类的分类厘定. 生物多样性, 29, 971-979. http://www.biodiversityscience.net/CN/10.17520/biods.2020320

近基部具一暗色纵纹(黑色素基本只分布于鳍膜); 胸鯺、腹鯺和慰鯺无黑色素分布; 尾鰙微黑色; 胃 和肠黑色; 腹膜银白色, 无黑色素分布。

新鲜标本体色与上述相近。各鯺及体侧具红 色素分布。新鲜标本照片见正文图2C及文献记录 (赵盛龙和钟俊生, 2006; 沈世杰和吴高逸, 2011; 刘 敏等, 2013)。

分类讨论。细条银口天竺鲷属于细条银口天 竺鲷种团。该种团还包含新几内亚银口天竺鲷、 横带银口天竺鲷和印度洋银口天竺鲷。具有以下 共同特征: 前鳃盖骨边缘具弱锯齿, 前鳃盖骨冷边 缘光滑; 后题骨后缘锯齿状; 体侧具暗色窄横带。 在该种团内, 细条银口天竺鲷与新几内亚银口天竺 鲷最为相似。两者的主要区别为: 细条银口天竺鲷 胸鯺鯺条数通常为 15 , 发达鳃耙数为13-15, 角鳃耙 数通常为9; 新几内亚银口天竺鲖胸鯺鯺条数通常 为 16 , 发达鳃耙数为 $10-12$, 角鳃耙数通常为 8 。

细条银口天竺鲷在中国黄渤海到南海都有分 布, 但其分布的中心区域为黄渤海到东海北部, 常 为优势种(刘勇等, 2006; 俞存根等, 2010; 任中华等, 2016), 南海甚为稀少。Gon (1997)认为细条银口天 竺鲷仅分布于中国和日本, 往南到台湾。 $\mathrm{Ng}$ 和 Lim (2014)使用一尾标本 (保存于 Raffles Museum of Biodiversity Research)报道了新加坡新纪录种细条 银口天竺鲷。Kelvin Kok Peng Lim检视的该标本具 有臀鯺下部黑色和覆膜具黑色素分布等特征。上 述形态特征与细条银口天竺鲖不同, 而与印度洋 银口天竺鲷相符, 推测该标本实为印度洋银口天 竺鲖。细条银口天竺鲖向南应分布至中国南部 沿海。

\section{3 新几内亚银口天竺鲷}

检视中国标本4尾, 体长61.3-79.7 mm。IOCAS 03232，79.7 mm，海南三亚，1956年11月 17 日; IOCAS 03233-03234, 2: 73.2-79.3 mm, 三亚, 1956 年12月4日; 无编号标本一尾, $61.3 \mathrm{~mm}$, 三亚, 1956 年11月17日。

其他标本。USNM ${ }^{\circledR}$ 68402, 80.25 mm, Amia albomarginata正模标本, 菲律宾吕宋岛, 在线X光 照片。

\footnotetext{
(1) Smithsonian Institution National Museum of Natural History
}

Apogon novaeguineae Valenciennes, 1832. Nouvelles Annales du Muséum d'Histoire Naturelle (Paris) v. 1: 53, Pl. 4 (fig. 1), 模式产地: 新几内亚。

Amia albomarginata Smith \& Radcliffe, 1912. Proceedings of the United States National Museum v. 41 (no. 1868): 438, Pl. 35 (fig. 2), 模式产地: 菲律宾 吕宋岛。

Apogonichthys albomarginatus: 白鳍拟天竺鲷, 成庆泰, 1959b. 动物学杂志, 8: 360; 白边天竺鱼, 成 庆泰等, 1962. 南海鱼类志: 336, 图280 (三亚); 白边 天答鱼, 成庆泰, 1987. 中国鱼类系统检索: 301, 图 1470。

Apogon albomarginatus: 白边天竺鲷, 刘瑞玉, 2008. 中国海洋生物名录: 974; 白边天竺鲷, 孙典荣 和陈铮, 2013. 南海鱼类检索: 459, 图820。

形态特征描述。背鯺鯺条数VII + I, 9; 臂鳍鳍 条数II, 8; 胸鯺鯺条数16-17 (通常为16); 腹鯺鯺条 数I, 5; 尾鳍鯺条数 $9+8$; 总鳃耙数 $4+11=15$; 发达 鳃耙数 $2+11=13$; 角鳃耙数 8 ; 背前鳞数 $4-5$ 。

上下领、犁骨、颚骨具细小圆锥状齿, 上下领 联合处齿略微膨大; 脊椎骨数 $10+14$, 具 3 枚上神经 骨、3枚尾上骨、5枚游离尾下骨; 尾神经骨缺失; 后题骨后缘具弱锯齿; 眶下骨腹缘光滑; 前鳃盖骨 边缘具弱锯齿, 前鳃盖骨脊边缘光滑无锯齿。

体色: 福尔马林溶液浸制标本体棕色, 背侧颜 色稍加深, 吻部仍具黑色素分布, 第一背鯺上端、 第二背鯺及尾鯺末端具黑色素分布。腹膜无黑色 素分布。

酒精浸制标本体浅棕色至棕色; 体侧无条带或 具多达 8 条模糊的棕色横带; 体侧侧线上方鳞囊末 端暗色; 头部背面和腹面均具微小暗色斑点; 吻部 及眼前区具微小暗色斑点; 颊部斜纹存在但通常不 明显; 大型雄性个体鳃盖后端黑色; 第一背鯺上部 微黑色; 第二背鯺和尾鯺浅色至微黑色, 末端颜色 加深; 第二背鯺有时于近基部具一不明显的暗色纵 纹; 腹鳍和慰鯺浅色; 腹膜浅色或零星地点缀着数 个微小暗色斑点; 肠浅色到黑色。

新鲜标本体色未知。

分类讨论。该种以其模式产地命名, 建议使用 “新几内亚银口天竺鲷” 作为该种的统一中文名。在 中国原记录为Apogonichthys albomarginatus (中文 
俞正森, 宋娜, 本村浩之, 高天翔 (2021) 中国银口天竺鲷属鱼类的分类厘定. 生物多样性, 29, 971-979. http://www.biodiversityscience.net/CN/10.17520/biods.2020320

名为白边拟天筑鲷或白边天筸鱼) (成庆泰, 1959b, 1987; 成庆泰等, 1962)。Gon (1997)检视了 Apogon novaeguineae和Amia albomarginata的正模标本及其 他凭证标本, 将后者列为前者的次定同种异名。虽 然之后仍有学者使用后者(Allen, 1999; Kottelat, 2013; Mabuchi et al, 2014), 但仅在名录中列出, 没有 讨论物种有效性。Hayashi (2004)从日本南部报道 了Apogon albomarginata, 将其标本与Gon (1997) 中 novaeguineae的手绘图比较, 发现其标本具有主上 领骨不伸达眼后缘、尾鯺截形、体侧无横带等特 征, 而在Gon (1997)的图示中, 主上领骨伸达眼后缘, 尾鯺圆形, 体侧具横带。因此推测其标本与 novaeguineae为不同物种, 其标本的上述特征与 albomarginata的原始图示(Plate 35, fig. 2, 见Smith \& Radcliffe, 1912) 相符, 故使用学名Apogon albomarginata。然而在Smith和Radcliffe (1912)的原 始描述中, “fins rounded”, 图示中尾鯺也为圆形。 Hayashi (2004)也许没有阅读文字描述, 而图示中不 显著的圆形尾鯺误导了Hayashi认为其为截形。

Gon (1997)的描述(“body pale or with up to eight fait dark brown bars”)包含体侧无横带和有横带两种情 况, 在其图示(根据标本RUSI ${ }^{2}$ 51351绘制)中, 体侧 具横带。Hayashi (2004)的标本体侧无横带不能有 力说明两命名种具显著差异。而仅与Gon (1997)的 图示比较, 未与模式标本比较, 另一特征(主上领骨 长度)也不具有说服力。因此, 本研究采纳 Gon (1997)的观点, 将albomarginata列为novaeguineae 的 次定同种异名。

新几内亚银口天竺鲷属于细条银口天竺鲷种 才, 与细条银口天竺鲷形态最为相似, 但可通过胸 鯺鯺条数和鳃耙数目予以区分(见细条银口天竺鲷 讨论)。与黑边银口天竺鲷种团可通过前鳃盖骨脊 (其边缘分别为光滑和具锯齿) 和发达上鳃耙数进行 区分(分别为 2 和 1 )。与斑鳛银口天竺鲷种团可通过 前鳃盖骨(其边缘分别为弱锯齿状和光滑)和上鳃耙 数目(分别为 2 和 1 )进行区分。

\section{4 黑鰓银口天竺鲷}

检视中国标本 39 尾, 体长 49.7-98.2 mm。 OUC_FEL AP140010-140021, 12: 65.9-92.0 mm, 海

\footnotetext{
(2) Rhodes University, J.L.B. Smith Institute of Ichthyology, 现已更名为 South African Institute for Aquatic Biodiversity (SAIAB)
}

南岛西北海域, 2014 年 9 月 2 日; OUC_FEL AP150779-150799, 21: 49.7-98.2 mm, 广西北海, 2015年8月8日; 未编号保存标本2尾, 体长70.1-84.7 $\mathrm{mm}$, 海南岛西北海域, 2014年9月3日; 未编号保存 标本1尾, 体长76.8 mm, 广西北海, 2015年8月10日; IOCAS 03277, $98.1 \mathrm{~mm}$,海南三亚, 1955年3月15日; IOCAS 03278-03279, 75.6-77.6 mm, 海南干冲, 1955年7月27日。

Apogon poecilopterus Cuvier in Cuvier \& Valenciennes, 1828. Histoire naturelle des poissons v. 2: 154, 模式产地: 印度尼西亚爪哇岛; Apogon (Jaydia) poecilopterus Gon, 1997. Transactions of the Royal Society of South Africa, 51, 1: 172, Figure 12 。

Apogonichthys arafurae: 黑鳃拟天竺鲖, 成庆泰, 1959b. 动物学杂志, 8: 360; 黑鳃天竺鱼, 成庆泰, 1962. 南海鱼类志: 334, 图278 (三亚、干冲、涠洲); 黑鳃天竺鱼, 成庆泰, 1987. 中国鱼类系统检索: 301, 图1468 (海南岛)。

Apogon arafurae: 黑鳃天竺鲷, 刘瑞玉, 2008. 中 国海洋生物名录: 974; 黑鳃天竺鲷, 孙典荣和陈铮, 2013. 南海鱼类检索: 457, 图811; 黑鳃天竺鲖, 陈大 刚和张美昭, 2016. 中国海洋鱼类: 1047。

形态特征描述。背鯺鯺条数VII + I, 9, 慰鯺鯺 条数II, 8, 胸鯺鯺条数15-17 (通常为16), 腹鯺鯺条 数I, 5, 尾鳍鯺条数 $9+8$; 总鳃耙数 $2-4+11-12=$ 13-16 (通常为3-4 + 11-12 = 14-16), 发达鳃耙数 $1+$ 9-11 = 10-12 (通常为 $1+10$ ), 角鳃耙数 8 ; 侧线鳞数 $24+3$, 侧线上鳞数 2 , 侧线下鳞数 6 , 背前鳞数 $4-5$, 为圆鳞。

前鳃盖骨边缘光滑无锯齿, 前鳃盖骨脊边缘光 滑无锯齿; 眶下骨缘光滑; 后颢骨后缘光滑; 上下 领、犁骨、颚骨具细小圆雉状齿, 上下领联合处齿 明显膨大; 脊椎骨数 $10+14$, 具 3 枚上神经骨、3枚 尾上骨、5枚游离尾下骨、2枚细长尾神经骨。体 大部具大型薄栉鳞, 背前区、颊部具圆鳞。

体色。酒精浸制标本体浅棕色至棕色, 头部背 侧及体背侧面颜色较深, 头部腹侧及体腹侧面颜色 浅; 吻部具黑色素分布, 呈浅棕色; 项部和题部斜纹 存在, 但均不明显; 头部腹面峡部至喉部具棕色小 斑点分布; 鳃腔、第一鳃弓及其鳃耙全为黑色; 体 
俞正森, 宋娜, 本村浩之, 高天翔 (2021) 中国银口天竺鲷属鱼类的分类厘定. 生物多样性, 29, 971-979. http://www.biodiversityscience.net/CN/10.17520/biods.2020320

侧通常具暗色斑纹和5-7不明显棕色横带; 第一背 鯺上部黑色; 第二背鯺具 1-3 (通常为1)暗色纵纹; 胸鲠和腹鯺大体浅色, 但胸鯺近基部处及基部通常 具黑色素分布, 腹鳍3-4鯺条末端有时具黑色素分 布; 慰鯺浅色, 近基部具一暗色纵纹; 尾鯺具黑色素 分布, 通常末端颜色加深; 腹膜无黑色素分布, 胃及 肠散布有小黑点。

新鲜标本体色与以上描述相近。但体侧横带 无或很不显著; 侧线下方斑纹无或不明显; 各鰙及 体侧具黄色分布(正文图2E, F)。

分类讨论。Cuvier (1828)简单描述了 Apogon poecilopterus。Gon (1997)检视了Cuvier的正模标本 及其他凭证标本。根据 Gon (1997), 该种 “Preopercular edge type C”(= smooth), "gill chamber, and at least first gill arch and its rakers dark brown to blackish”。Günther (1880) 于阿拉弗拉海描述了 Apogon arafurae, 其原始描述中, “Both limbs of the preoperculum are serrated; ... second dorsal and anal with a black band along the middle; upper margin of the second dorsal and posterior margin of the caudal black” (plate 16, fig. c见Günther, 1880), 上述特征与 黑边银口天竺鲖相符。但在我国专著的记录中, 该 种“鳃腔及鳃耙均为黑色” (成庆泰, 1959b); “前鳃盖 骨边缘平滑...每一鳞片具黑色边缘...第二背鯺及 尾鯺灰褐色” (成庆泰等, 1962); 孙典荣和陈铮 (2013)、陈大刚和张美昭(2016)的描述与上述基本 相同。而且本研究检视的标本IOCAS 03278-03279 (《南海鱼类志》中标本编号分别为35562和35563) 前鳃盖骨及其脊边缘光滑, 第二背鯺和尾鯺无黑色 边缘, 其他标本的特征与上述相同。综上所述, 中 国记录的Apogonichthys arafurae (黑鳃拟天竺鲖、 黑鳃天竺鱼) (成庆泰, 1959b, 1987; 成庆泰等, 1962) 和Apogon arafurae (黑鳃天竺鲖) (孙典荣和陈铮, 2013; 陈大刚和张美昭, 2016)与poeciloptera形态特 征相符, 而与arafurae不符。故可以推断我国记录 的物种实为Jaydia poeciloptera。中国鱼类学者(成 庆泰等, 1962; 孙典荣和陈铮, 2013; 陈大刚和张美 昭, 2016)使用的中文名 “黑鳃”贴切地表明了该种的 一个独征(鳃腔、第一鳃弓及其鳃耙均为黑色), 且 为常用名, 建议仍使用 “黑鳃银口天䇥鲖” 为该种统 一中文名。
黑鳃银口天竺鲖不同的地理群体第二背鯺和 臀鯺的颜色常具有显著的种内变化(Gon, 1997)。本 研究检视的标本臀鯺颜色无显著变异, 均为浅色于 近基部具一纵纹, 背鯺变异较大, 具1-3纵纹。黑鳃 银口天竺鲖具有两个独征, 即鳃腔、第一鳃弓及其 鳃耙均为黑色和上下领联合处齿明显膨大, 可据此 与同属其他物种区分。

\section{Jaydia sp.}

检视中国标本 11 尾, 体长62.1-98.6 mm。 OUC_FEL AP150553, 95.3 mm, 海南岛西北海域, 2014年9月1日; OUC_FEL AP150620-150628，9， 62.1-98.6 mm, 广东珠海, 2014 年 11 月 20 日; OUC_FEL AP150858, 71.5 mm, 浙江舟山, 2015年 10月20日。

形态特征描述。背鯺鯺条数VII + I, 9, 臂鳍鳍 条数II, 8, 胸鯺鯺条数 16-17, 腹鳍鯺条数I, 5, 尾鳍 鯺条数 $9+8$; 总鳃耙数 $2-4+11-12=13-16$ (通常为 $3-4+11-12=14-16)$, 发达鳃耙数 $1+9-11=10-12$ (通常为 $1+10$ ) 角鳃耙数 8 ; 侧线鳞数 $24+3$, 侧线上 鳞数 2 , 侧线下鳞数 6 , 背前鳞数 $4-5$ 。

前鳃盖骨边缘锯齿状, 前鳃盖骨脊边缘转折处 具弱锯齿; 眶下骨边缘锯齿状; 后䩂骨后缘弱锯齿 状; 上下领、犁骨、㓵骨具细小圆雉状齿, 上下领 联合处齿稍膨大; 脊椎骨数 $10+14$, 具 3 枚上神经 骨、3枚尾上骨、5枚游离尾下骨、2枚尾神经骨。 体大部具大型薄栉鳞, 背前区、项部具圆鳞。

分类讨论。史密斯氏银口天竺鲖为Kotthaus (1970)根据亚丁湾标本描述的新种。Gon (1997)的 研究结果表明史密斯氏银口天筑鲷的分布范围为 印度洋北部到西太平洋, 其检视的标本包含采集自 中国香港、澳门和台湾的标本。近年来, 史密斯氏 银口天竺鲖从红海经由苏伊士运河入侵到了地中 海(Golani et al, 2008; Goren et al, 2009; Gökoğlu et al, 2010; Al-Shawy et al, 2017)。比较中国种群和地 中海种群的形态特征(表A1), 没有发现有效的形态 特征可以将两者区分开, 中国种群和地中海种群均 可鉴定为史密斯氏银口天竺鲷。本研究使用DNA 条形码序列进行遗传学分析, 计算种群间与种群内 遗传距离, 结果显示中国种群和地中海种群组间遗 传距离为 0.044 , 远大于两种群组内遗传距离, 也远 远大于一般的鱼类种内遗传距离, 为种间差异水平 
俞正森, 宋娜, 本村浩之, 高天翔 (2021) 中国银口天竺鲷属鱼类的分类厘定. 生物多样性, 29, 971-979. http://www.biodiversityscience.net/CN/10.17520/biods.2020320

(表A2)。以黑似天筑鲷和犬牙拟天䇥鲷为外群, 使 用DNA条形码序列重建银口天竺鲷属系统发育树, 结果显示史密斯氏银口天竺鲷中国种群和地中海 种群都为具有排他性的世系, 两者形成姐妹群关系, 且与其他银口天竺鲖属鱼类明显分开。结果提示 其中存在隐存种。而史密斯氏银口天答鲷的模式 产地为亚丁湾。推测地中海种群为真正的史密斯
氏银口天竺鲷, 中国种群为隐存种Jaydia sp., Gon (1997)在中国记录的史密斯氏银口天箨鲖应为 Jaydia sp.。

在中国海域, Jaydia sp. 与黑边银口天竺鲷最为 相似, 但可通过慰鯺纵纹有无和头顶斑点进行区分, 前者臀鯺中部无纵纹, 头顶斑点小而密, 后者慰鯺 中部具一黑色纵纹, 头顶斑点大而稀疏。

表A1 本研究使用标本与已有文献中史密斯氏银口天矢鲷形态特征比较

Table A1 Morphological comparison between Jaydia sp. in this study and Jaydia smithi in references

\begin{tabular}{|c|c|c|c|c|c|}
\hline 特征 Characters & $\begin{array}{l}\text { 本研究 This study } \\
(\mathrm{n}=11)\end{array}$ & $\begin{array}{l}\text { Gon, 1997 } \\
(\mathrm{n}=123)\end{array}$ & $\begin{array}{l}\text { Golani et al, } \\
2008(\mathrm{n}=6)\end{array}$ & $\begin{array}{l}\text { Goren et al, } \\
2009(\mathrm{n}=7)\end{array}$ & $\begin{array}{l}\text { Gökoğlu et al, } \\
2010(\mathrm{n}=32)\end{array}$ \\
\hline 背鰖鰙条数 & $\mathrm{VII}+\mathrm{I}, 9$ & VII + I, 9 & VII + I, 9 & VII + I, 8-9 (9) & VII + I, 9 \\
\hline 臀鰙鯺条数 & II, 8 & II, 8 & II, 8 & II, 7-8 (8) & II, 8 \\
\hline 胸鳍鳍条数 & $16-17$ & $15-17(16)$ & $15-16(16)$ & 15 & 15 \\
\hline 侧线鳞数 & $24+3$ & $26-28(27)$ & $24+3$ & $24-26+1-2$ & $24-26+1-2$ \\
\hline 背前鳞数 & $4-5$ & $3-5(4)$ & 5 & $4-5$ & $4-5$ \\
\hline 总鳃耙数 & $3+11-12=14-15$ & $3-5+10-13=13-17$ & $3-4+11$ & & \\
\hline 发达鳃耙数 & $1+9-10=10-11$ & $1+9-11=10-12$ & $1-2+11$ & $1+9-11$ & $1+9-11$ \\
\hline 角鳃耙数 & 8 & $8-9(8)$ & 8 & & \\
\hline \multicolumn{6}{|l|}{ 测量特征 } \\
\hline 体高/体长 & $27.7-33.2(29.35)$ & $29.4-35.7$ & $29.4-34.5$ & 28.1-35.9 (32.9) & $28.2-35.7(32.0)$ \\
\hline 头长/体长 & $39.3-41.9(40.5)$ & $38.5-43.5$ & $40.0-45.5$ & $33.4-35.9(34.6)$ & \\
\hline 胸鯺长/体长 & $19.75-22.25$ (20.9) & $19.2-23.8$ & & & \\
\hline 腹鯺长/体长 & $19.3-22.1(21.25)$ & $20.2-26.3$ & & & \\
\hline 头长/吻长 & $5.6-6.2$ & $5.0-6.95$ & $4.85-6.6$ & & \\
\hline 头长/眼径 & $3.5-3.75$ & $3.3-4.3$ & $3.3-4.2$ & & \\
\hline 头长/眼间距 & $4.65-5.2$ & $4.2-5.5$ & $4.3-5.7$ & & \\
\hline
\end{tabular}

$\mathrm{n}$ 为样品数量。

表A2 使用COI基因片段计算Jaydia sp.和Jaydia smithi个体间K2P遗传距离

Table A2 Genetic distance (Kimura 2-P) between cytochrome oxidase subunit I (COI) gene of individuals of Jaydia sp. and Jaydia smithi

\begin{tabular}{|c|c|c|c|c|c|c|c|c|}
\hline \multirow{2}{*}{$\begin{array}{l}\text { 物种 } \\
\text { Species }\end{array}$} & \multirow{2}{*}{$\begin{array}{l}\text { 标本 } \\
\text { Specimens }\end{array}$} & \multicolumn{5}{|c|}{ Jaydia sp. } & \multicolumn{2}{|l|}{ Jaydia smithi } \\
\hline & & 150553 & 150858 & 150620 & 150622 & 150625 & KM5381761 & KR861533 \\
\hline \multirow[t]{5}{*}{ Jaydia sp. } & 150553 & & & & & & & \\
\hline & 150858 & 0.011 & & & & & & \\
\hline & 150620 & 0.008 & 0.004 & & & & & \\
\hline & 150622 & 0.009 & 0.002 & 0.002 & & & & \\
\hline & 150625 & 0.011 & 0.008 & 0.004 & 0.006 & & & \\
\hline \multirow[t]{2}{*}{ Jaydia smithi } & KM5381761 & 0.040 & 0.049 & 0.044 & 0.047 & 0.047 & & \\
\hline & KR861533 & 0.042 & 0.051 & 0.046 & 0.048 & 0.048 & 0.002 & - \\
\hline
\end{tabular}

$\mathrm{n}$ 为样品数量。

\section{6 横带银口天尔鲷}

检视标本：OUC_FEL 20200001-20200008, 8, 40.7-53.1 mm, 三亚蜈支洲岛, 2019年10月11日。

比较的标本。Jaydia striatodes: IOCAS 03258 (56-2530), $50.0 \mathrm{~mm}$, 汕尾, 1956年10月18日; IOCAS 03259 (56-5026), $50.5 \mathrm{~mm}$, 东平, 1956年3月27日; IOCAS 03260 (35280), 53.3-54.3 mm, 新村, 1955年 11月21日; IOCAS 03261 (35282), 新村, 1955年11月 21日。括号内为成庆泰等(1962)中的标本编号。
Amia striata: Smith \& Radcliffe in Radcliffe, 1912. Proceedings of the United States National Museum v. 41 (no. 1868):437, Pl. 35 (fig. 1), 模式产 地: 菲律宾吕宋岛西岸。

Apogonichthy striatus: 宽条拟天竺鲷, 成庆泰, 1959b. 动物学杂志, 8: 360; 宽条天竺鱼, 成庆泰等, 1962. 南海鱼类志: 333, 图276 (汕尾、三亚、新 村、东平); 宽条天竺鱼, 沈根媛, 1985. 福建鱼类志: 48, 图378 (福鼎沙埕、霞浦三沙、东山); 宽条天竺 
俞正森, 宋娜, 本村浩之, 高天翔 (2021) 中国银口天竺鲷属鱼类的分类厘定. 生物多样性, 29, 971-979. http://www.biodiversityscience.net/CN/10.17520/biods.2020320

鱼, 成庆泰, 1987. 中国鱼类系统检索: 301, 图 1466。

Apogon striatus: 条纹天竺鲷, 沈世杰, 1993. 台 湾鱼类志: 316, 图版84-3; 横带天竺鲷, 刘瑞玉, 2008. 中国海洋生物名录: 976; 条纹天笛鲷, 沈世杰和吴 高逸, 2011. 台湾鱼类图鉴: 406; 横带天竺鲷, 孙典 荣和陈铮, 2013. 南海鱼类检索: 458, 图813; 横带天 竺鲷, 陈大刚和张美昭, 2016. 中国海洋鱼类: 1050 。

形态特征描述。背鯺鯺条数 VII + I, 9, 臂鯺鯺 条数II, 8, 胸鯺鯺条 15 , 腹鯺鯺条数I, 5, 尾鰙鯺条数 $9+8$; 总鳃耙数 $3-4+11-13=15-17$, 发达鳃耙数 $2+$ 11 , 角鳃耙数 9 ; 侧线鳞数 $24+3$, 侧线上鳞数 2 , 侧线 下鳞数 6 , 背前鳞数 $3-4$ 。

前鳃盖骨边缘锯齿状, 前鳃盖骨脊边缘转折处 光滑; 眭下骨边缘光滑; 后题骨后缘弱锯齿状; 上下 领、犁骨、颚骨具细小圆锥状齿, 上下领联合处齿 稍膨大; 脊椎骨数 $10+14$, 具3枚上神经骨、3枚尾 上骨、5枚游离尾下骨, 尾神经骨缺失。

体色。酒精浸制标本体浅棕色至棕色, 头部背 侧及体背侧面颜色较深, 头部腹侧及体腹侧面颜色 浅; 吻部具黑色素分布, 呈棕色; 颊部具一棕色斜纹; 头部腹面具黑色素; 鳃腔和鳃浅色; 体侧具7-12 (通常为8-10)棕色窄横带, 带宽略等于带间距; 第 一背鯺上部微黑色; 胸鯺、腹鯺和臀鯺无黑色素 分布; 尾鯺微黑; 胃和肠黑色; 腹膜银白色, 具黑色 素分布。

分类讨论。横带银口天竺鲷属于细条银口天 竺鲷种团, 与印度洋银口天竺鲷为姐妹群, 形态非 常相似, 但是可通过鳃耙数和臀鯺颜色进行区分。 前者具2发达上鳃耙且其臀鯺浅色, 仅在大型个体 $(>$ $60 \mathrm{~mm})$ 中臀鯺下部具黑色素分布; 后者具3发达上 鳃耙, 且其臀鯺下部具黑色素。Gon (1997)描述了 另一区别, 即横带银口天竺鲖具8角鳃耙, 而印度洋 银口天竺鲷具 9 角鳃耙。但本研究所检视的 8 尾横 带银口天竺鲷标本的角鳃耙数也为 9 。

成庆泰(1959b)最早从中国记录了横带银口天 竺鲖, 并做简单描述, 但没有标本信息的描述。成 庆泰等(1962)对该种做了较为详细的描述, 包含标 本信息的不完整描述。两次记述的地点完全吻合 表明其使用了相同的标本。沈根媛(1985)从中国福
建沿海记录了横带银口天䇥鲷, 没有标本信息的描 述。Gon (1997)从中国台湾东港记录了横带银口天 竺鲖, 从中国香港记录了印度洋银口天竺鲷。本研 究检视了成庆泰等(1962)记录的10尾标本中的4尾, 证实其为印度洋银口天䇥鲖, 其余标本未见。由于 没有描述标本信息, 成庆泰(1959)和沈根媛(1985)的 记录已不可考证。因此, 该种在我国的分布范围需 要依据新采标本进行重新阐述。

\section{7 印度洋银口天竺鲷}

Apogon (Jaydia) striatodes Gon, 1997. Transactions of the Royal Society of South Africa, 51, 1: 179, Fig. 15, 模式产地: 安达曼海泰国西岸。

Apogon lineatus: 细条天竺鲷, 赖廷和和何斌源, 2016. 广西北部湾海洋硬骨鱼类图鉴: 146。

形态特征描述。背鯺鯺条数VII + I, 9, 臂鳍鳍 条数II, 8, 胸鯺鯺条 15 , 腹鳍鯺条数I, 5 , 尾鯺鯺条数 $9+8$; 总鳃耙数 $4-6+11-13=16-19$, 发达鳃耙数 $2-$ $3(3)+11-12=14-15$, 角鳃耙数 9 ; 侧线鳞数 $24+3$, 侧线上鳞数 2 , 侧线下鳞数 6 , 背前鳞数 4 。

前鳃盖骨边缘锯齿状, 前鳃盖骨脊边缘转折处 光滑; 眭下骨边缘光滑; 后欼骨后缘弱锯齿状; 上下 领、犁骨、颚骨具细小圆雉状齿, 上下领联合处齿 稍膨大; 脊椎骨数 $10+14$, 具 3 枚上神经骨、3枚尾 上骨、5枚游离尾下骨, 尾神经骨缺失。体大部具 大型薄栉鳞, 头部及体前端具少量圆鳞。

体色。酒精浸制标本体浅棕色至棕色, 头部背 侧及体背侧面颜色较深, 头部腹侧及体腹侧面颜色 浅; 吻部具黑色素分布, 呈棕色; 颊部具一棕色斜纹; 头部腹面具黑色素; 鳃腔和鳃浅色; 体侧通常具 810 棕色窄横带, 带宽略等于带间距; 第一背鯺上部 微黑; 胸鯺、腹鯺无黑色素分布; 慰鯺下端通常具 一黑色素带, 尾鯺微黑; 胃和肠黑色; 腹膜银白色, 具黑色素点分布。

新鲜标本体色与上述相似, 但体及各鳍具红色 分布。

分类讨论。Gon (1997)描述了新种印度洋银口 天答鲖Apogon (Jaydia) striatodes, 其副模标本包含 采自香港的标本。该种在中国被误鉴为横带银口 天竺鲖, 两者形态非常相似, 但可通过鳃耙数和臀 鯺颜色进行区分(见横带银口天竺鲷讨论)。Yu等 (2016)证实了印度洋银口天竺鲖的有效性及其与横 
俞正森, 宋娜, 本村浩之, 高天翔 (2021) 中国银口天竺鲷属鱼类的分类厘定. 生物多样性, 29, 971-979. http://www.biodiversityscience.net/CN/10.17520/biods.2020320

带银口天竺鲖的姐妹群关系, 且证实鳃耙数和慰鯺 颜色的细微差异即可区分两物种。

\section{8 烟台银口天竺鲷}

Apogon tchefouensis Fang, 1942: 80, 模式产地: 中国山东烟台。

检视标本: 无标本。

分类讨论。Fang (1942) 从中国烟台描述了 Apogon tchefouensis, 其模式系列包含 1 尾正模标本 和2尾副模标本。然而到目前为止, 没有新的烟台 银口天竺鲷标本被报道。Fraser (2000)检视了该命 名种的两尾副模标本, 认为其为细条银口天竺鲖、 横带银口天筑鲷或印度洋银口天竺鲷之一的异名, 且如果已知的分布准确, 大的一尾副模标本可鉴定 为细条银口天竺鲷。Mabuchi等(2014)在其名录中 列出烟台银口天竺鲷, 但不确定其是否为细条银口 天竺鲷次异名或印度洋银口天竺鲷首异名。除细 条银口天竺鲖外, 细条银口天竺鲖种团的其他物种 往北最多分布到台湾。因此, 烟台银口天竺鲷可能 为细条银口天竺鲖的次异名。

\section{9 黑边银口天竺鲷}

检视中国标本56尾, 体长39.9-110.5 mm。CAS 0601 (两尾中大的一尾, 小的一尾为斑鯺银口天竺 鲷), $112 \mathrm{~mm}$, 粤东沿海, 1982年8月9日; IOCAS 03006, $51.0 \mathrm{~mm}$, 盐田, 1956年12月27日; IOCAS 02993，62.1 mm，盐田，1956年12月27日; IOCAS 02996-02998, 3: 42.7-68.3 mm, 白马林, 1964年5月 20日; OUC_FEL AP140007-1400009, 3: 83.1-97.0 $\mathrm{mm}$, 海南岛西北海域, 2014年9月2日; OUC_FEL AP150718-150720, 3: 68.1-76.4 mm, 广东大亚湾, 2015年4月13日; OUC_FEL AP150768-150778, 11: 71.5-94.3 mm, 广西北海, 2015 年 8 月 8 日; ZJOU_FEBL 150579-150584, 6: 39.9-56.1 mm, 浙 江舟山，2015年10月20日; OUC_FEL AP150830, $50.3 \mathrm{~mm}$, 福建东山岛, 2015年10月30日; OUC_FEL AP160085, $77.1 \mathrm{~mm}$, 广西防城港, 2016年1月20日; 未编号保存标本25尾, 81.2-110.5 mm, 海南岛西北 海域, 2014年9月1日。

Apogon truncatus Bleeker, 1854. Natuurkundig Tijdschrift voor Nederlandsch Indië v. 7 (no. 3): 415, 模式产地: 印度尼西亚爪哇岛。
Apogonichthys ellioti: 爱氏天竺鱼, 王以康, 1958. 鱼类分类学, 292; 黑边拟天竺鲖, 成庆泰, 1959a. 中国动物图谱 鱼类(第四册): 16, 图32; 黑边 拟天竺鲖, 成庆泰, 1959b. 动物学杂志, 8: 361; 黑边 天筸鱼, 成庆泰等, 1962. 南海鱼类志: 338, 图282 (盐田、涠洲、北海、清澜、闸坡); 黑边天答鱼, 沈 根媛, 1985. 福建鱼类志(下卷): 51, 图382 (平潭东 庠、厦门、三沟渔场、台湾堆); 黑边天䇥鱼, 成庆 泰, 1987. 中国鱼类系统检索: 301, 图1471; 黑边天 竺鱼, 李金平等, 1999. 澳门鱼类: 87。

Apogon ellioti: 黑边天竺鲖, 沈世杰, 1984. 台湾 鱼类检索: 236; 黑边天竺鲷, 沈世杰, 1993. 台湾鱼 类志: 311, 图版81-9; 黑边天竺鲷, 刘瑞玉, 2008. 中 国海洋生物名录: 975; 黑边天竺鲷, 沈世杰和吴高 逸, 2011. 台湾鱼类图鉴: 400; 黑边天竺鲷, 孙典荣 和陈铮, 2013. 南海鱼类检索: 458, 图815; 黑边天竺 鲖, 刘敏等, 2014. 中国福建南部海洋鱼类图鉴: 148; 黑边天竺鲖, 陈大刚和张美昭, 2016. 中国海洋鱼类: 1049。

Jaydia truncate: 截尾天竺鲖, 赖廷和和何斌源, 2016. 广西北部湾海洋硬骨鱼类图鉴: 157 。

形态特征描述。背鯺鯺条数VII + I, 9, 臀鳍鯺 条数II, 8, 胸鯺鯺条数16-18 (通常为17), 腹鯺鯺条 数I, 5, 尾鳍鯺条数 $9+8$; 总鳃耙数 $3-4+11-13=$ 14-17, 发达鳃耙数 $1+9-11=10-12$, 角鳃耙数 $8-9$ (通常为 8 ); 侧线鳞数 $24+3$, 侧线上鳞数 2 , 侧线下鳞 数6, 背前鳞数 $3-4$ (通常为 3 ), 为圆鳞。

前鳃盖骨边缘锯齿状, 前鳃盖骨脊边缘转折处 具锯齿; 眶下骨边缘弱锯齿状; 后颢骨后缘弱锯齿 状; 上下领、犁骨、㓵骨具细小圆雉状齿, 上下领 联合处齿略微膨大; 脊椎骨数 $10+14$, 具 2 枚上神经 骨、3枚尾上骨、5枚游离尾下骨、2枚尾神经骨。 体大部具大型薄栉鳞, 背前区、颊部和峡部至喉部 具圆鳞。

体色。酒精浸制标本体浅棕色至棕色, 头部背 侧及体背侧面颜色较深, 头部腹侧及体腹侧面颜色 浅; 吻部具黑色素分布, 呈棕色; 㚘部具一棕色斜纹 自眼下缘延伸至颊部下方; 颢部具一斜向上的棕色 短条纹; 头部腹面从缝合部到胸部具黑色素分布, 缝合部和卧部黑色素斑点小, 峡部和胸部黑色素斑 点大; 鳃和鳃腔浅色; 体侧通常具4-7条棕色横带(新 
俞正森, 宋娜, 本村浩之, 高天翔 (2021) 中国银口天竺鲷属鱼类的分类厘定. 生物多样性, 29, 971-979. http://www.biodiversityscience.net/CN/10.17520/biods.2020320

鲜时有时无或不明显); 第一背鯺上部黑色; 第二背 鯺中部和边缘各具一黑色纵纹; 胸鯺和腹鯺通常具 少量黑色素散布, 但不成条纹状; 慰鯺中部具一黑 色纵纹; 尾鯺边缘黑色; 胃及肠具黑色素覆盖; 腹膜 银白色, 密布黑色斑点。

新鲜标本体色与以上描述相近。但体侧之横 带有时无或不显著; 身体和各鯺具浅红色或黄色分 布。新鲜标本照片见正文图2J及文献记录(刘静等, 2015; 陈大刚和张美昭, 2016; 赖廷和和何斌源, 2016)。沈世杰(1993, 图版81)和沈世杰和吴高逸 (2011)记录的黑边银口天竺鲷标本照片臀鯺中部无 暗色纵纹, 应为对Jaydia sp.的误鉴。

分类讨论。黑边银口天筑鲖在中国以学名 Apogon ellioti和Apogonichthys ellioti记录(成庆泰等, 1962; 刘敏等, 2014; 陈大刚和张美昭, 2016)。赖廷 和和何斌源(2016)以学名Jaydia truncate (拼写错误) 记录了本种。黑边银口天竺鲖的正确学名为Jaydia truncata, 其学名使用已由俞正森等(2017)更正。沈 世杰(1993)记录的黑边银口天竺鲖臂鯺无黑色纵纹, 应为对Jaydia sp. 误鉴。

黑边银口天竺鲖属于黑边银口天竺鲷种团, 形 态上与史密斯氏银口天竺鲖和Jaydia sp. 非常相似, 但可通过臀鯺中部的暗色纵纹和头顶部显著的暗 色斑点与后者区分(见Jaydia sp.讨论)。

\section{参考文献}

Akyol O, Ünal V (2015) Additional record of the Lessepsian Apogon queketti Gilchrist, 1903 (Osteichthyes: Apogonidae) from the Aegean Sea (Gökova Bay, Turkey). Journal of Applied Ichthyology, 31, 536-537.

Allen GR (1999) Family Apogonidae. In: FAO Species Identification Guide for Fisheries Purposes. The Living Marine Resources of the Western Central Pacific. Bony Fishes Part 2 (Mugilidae to Carangidae) (eds Carpenter KE, Niem VE), pp. 2602-2610. FAO, Rome.

Al-Shawy FA, Lahlah MM, Hussein CS (2017) First record of the Lessepsian migrant Smith's Cardinalfish Jaydia smithi Kotthaus, 1970 (Pisces: Apogonidae) from Syrian marine waters. Basrah Journal of Agricultural Sciences, 30(2), 4549.

Chen DG, Zhang MZ (2016) Marine Fishes of China, pp. 1010-1059. China Ocean University Press, Qingdao. (in Chinese) [陈大刚, 张美昭 (2016) 中国海洋鱼类, 10101059页. 中国海洋大学出版社, 青岛.]

Cheng QT (1955) Family Apogonidae. In: Fish Survey of the
Bohai Sea and Yellow Sea (eds Zhang CL, Cheng QT, Zheng BS), pp. 98-99. Science Press, Beijing. (in Chinese) [成庆泰 (1955) 黄渤海鱼类调查报告, 98-99页. 科学出版 社, 北京.]

Cheng QT (1959a) Illustration of Chinese Animals (Fish, Volume 4), pp. 14-18. Science Press, Beijing. (in Chinese) [成庆泰 (1959a) 中国动物图谱(鱼类第4册), 14-18页. 科 学出版社, 北京.]

Cheng QT (1959b) A checklist of the cardinalfishes (Percomorpha: Apogonidae) in China and new records. Chinese Journal of Zoology, 8, 359-362. (in Chinese) [成庆 泰 (2015) 我国的天竺鲷科鱼类及其新纪录. 动物学杂志, 8, 359-362.]

Cheng QT (1963) Family Apogonidae. In: Fishes in the East China Sea (eds Zhu YD, Zhang CL, Cheng QT), pp. 233238. Science Press, Beijing. (in Chinese) [成庆泰 (1963) 天 竺鲷科. 见: 东海鱼类志(朱元鼎, 张春霖, 成庆泰主编), 233-238页. 科学出版社, 北京.]

Cheng QT (1987) Family Apogonidae. In: Systematic Synopsis of Chinese Fishes (eds Cheng QT, Zheng BS), pp. 300-303. Science Press, Beijing. (in Chinese) [成庆泰 (1987) 天竺鲷 科. 见: 中国鱼类系统检索(成庆泰, 郑葆珊主编), 300-303 页. 科学出版社, 北京.]

Cheng QT (1997) Family Apogonidae. In: The Fishes of Shandong Province (eds Cheng QT, Zhou CW), pp. 256257. Shandong Science and Technology Press, Ji'nan. (in Chinese) [成庆泰 (1997) 天竺鲖科. 见: 山东鱼类志 (成庆 泰, 周才武主编), 256-257页. 山东科学技术出版社, 济 南.]

Cheng QT, Wang CX, Tian MC, Yang WH, Sun BL (1962) Family Apogonidae. In: Fishes in the South China Sea (eds Zhu YD, Zhang CL, Zhang YW et al), pp. 328-347. Science Press, Beijing. (in Chinese) [成庆泰, 王存信, 田明诚, 杨文 华, 孙宝龄 (1962). 天竺鲷科. 见: 南海鱼类志(朱元鼎, 张 春霖, 张有为等主编), 328-347页. 科学出版社, 北京.]

Cuvier G (1828) Des apogons. In: Histoire naturelle des poisons, 2 (eds Cuvier G, Valenciennes A), pp. 145-160. F.G. Levrault, Paris.

Eryilmaz L, Dalyan C (2006) First record of Apogon queketti Gilchrist (Osteichthyes: Apogonidae) in the Mediterranean Sea. Journal of Fish Biology, 69, 1251-1254.

Fang PW (1942) Poissons de Chine de M. Ho: Description de cinqespècesetdeux sous-espècesnouvelles. Bulletin de la Société Zoologique de France, 67, 79-85.

Fraser T H (2000) A new species of Apogon (Perciformes: Apogonidae) from the Saya de Malha Bank, Indian Ocean, with redescriptions of Apogon regani Whitley, 1951, A. gardineri Regan, 1908, and A. heraldi (Herre, 1943). Proceedings of the Biological Society of Washington, 113, 249-263.

Gökoğlu M, Özgür Özbek E, Kebapçioğlu T, Balci BA, Kaya Y (2010) The second location records of Apogon smithi and 
俞正森, 宋娜, 本村浩之, 高天翔 (2021) 中国银口天竺鲷属鱼类的分类厘定. 生物多样性, 29, 971-979. http://www.biodiversityscience.net/CN/10.17520/biods.2020320

Vanderhorstia mertensi (Pisces) from the Turkish Coast of the Mediterranean Sea. Marine Biodiversity Records, 3(e83), 1-3.

Golani D, Appelbaum-Golani B, Gon O (2008) Apogon smithi (Kotthaus, 1970) (Teleostei: Apogonidae), a Red Sea cardinalfish colonizing the Mediterranean Sea. Journal of Fish Biology, 72, 1534-1538.

Gon O (1997) Revision of the cardinalfish subgenus Jaydia (Perciformes, Apogonidae, Apogon). Transactions of the Royal Society of South Africa, 51, 147-194.

Goren M, Yokes MB, Galil BS, Diamant A (2009) Indo-Pacific cardinal fish in the Mediterranean Sea-New records of Apogon smithi from Turkey and A. queketti from Israel. Marine Biodiversity Records, 2(e95), 1-4.

Günther A (1880) Report on the shore fishes procured during the voyage of H. M. S. Challenger in the years 1873-1876. Challenger Report on Zoology, 1(6), 1-82, Pls. 1-32.

Hayashi M (2004) First record of apogonid fish, Apogon albomarginata (Pisces: Apogonidae) from Ryukyu Islands, southwestern Japan. Science Report of the Yokosuka City Museum, 51, 46-52.

Huang KQ, Xu CY (1990) Family Apogonidae. In: The Fishes of Shanghai Area (eds Ni Y, Zhang LS, Zhang GX), pp. 254-255. Shanghai Scientific \& Technical Publishers, Shanghai. (in Chinese) [黄克勤, 许成玉 (1990) 天焦鲷科. 见: 上海鱼类志 (倪勇, 张列士, 张国祥主编), 254-255页. 上海科学技术出版社, 上海.]

Kottelat M (2013) The fishes of the inland waters of southeast Asia: A catalogue and core bibiography of the fishes known to occur in freshwaters, mangroves and estuaries. Raffles Bulletin of Zoology, 27(Suppl.), 1-663.

Kotthaus A (1970) Fische des Indischen Ozeans. Ergebnisse der ichthyologischen Untersuchungen während der Expedition des Forschungsschiffes 'Meteor' in den Indischen Ozean, Oktober 1964 bis Mai 1965. A. Systematischer Teil VIII Percomorphi (2). Meteor Forschungsergebnisse. Reihe D, Biologie No. 6, 56-75.

Lai TH, He BY (2016) Marine Osteichthyes Fishes in Guangxi Beibu Gulf of China, pp. 154-159. Science Press, Beijing (in Chinese) [赖廷和, 何斌源 (2016) 广西北部湾海洋硬骨 鱼类图鉴, 154-159页. 科学出版社, 北京.]

Li JP, Yang TB, Liang ZH, Huang X (1999) Fishes of Macao, pp. 86-89. Maritime Museum, the Association for Promotion of Science and Technology of Macao, Macao. (in Chinese) [李金平, 杨廷宝, 梁之华, 黄晓 (1999) 澳门鱼类, 86-89页. 海事博物馆, 澳门科学技术协进会, 澳门.]

Liu J, Chen YX, Ma L (2015) Fishes of the Bohai Sea and Yellow Sea, pp. 151. Science Press, Beijing. (in Chinese) [刘静, 陈咏霞, 马琳 (2015) 黄渤海鱼类图志, 151页. 科学 出版社, 北京.]

Liu M, Chen X, Yang SY (2013) Marine Fishes of Southern Fujian, China (Volume 1), pp. 155-159. China Ocean Press,
Beijing. (in Chinese) [刘敏, 陈骁, 杨圣云 (2013) 中国福建 南部海洋鱼类图鉴第一卷, 155-159页. 海洋出版社, 北 京.]

Liu M, Chen X, Yang SY (2014) Marine Fishes of Southern Fujian, China (Volume 2), pp. 148-151. China Ocean Press, Beijing, (in Chinese) [刘每, 陈骁, 杨圣云 (2014) 中国福建 南部海洋鱼类图鉴第二卷, 148-151页. 海洋出版社, 北 京.]

Liu PT, Deng SM (2006) Family Apogonidae. In: Fishes of Jiangsu Province (eds Ni Y, Wu HL), pp. 501-504. China Agriculture Press, Beijing. (in Chinese) [刘培廷, 邓思明 (2006) 天竺鲷科. 见: 江苏鱼类志(倪勇, 伍汉霖主编), 501-504页. 中国农业出版社, 北京.]

Liu RY (2008) Checklist of Marine Biota of China Seas, pp. 974-978. Science Press, Beijing. (in Chinese) [刘瑞玉 (2008) 中国海洋生物名录, 974-978页. 科学出版社, 北 京.]

Liu Y, Li SF, Cheng JH (2006) A study of seasonal changes of fish communities in the East China Sea and Huanghai Sea. Acta Oceanologica Sinica, 28(4), 108-114. (in Chinese with English abstract) [刘勇, 李圣法, 程家骅 (2006) 东海、黄 海鱼类群落结构的季节变化研究. 海洋学报, 28(4), 108114.]

Mabuchi K, Fraser TH, Song H, Azuma Y, Nishida M (2014) Revision of the systematics of the cardinalfishes (Percomorpha: Apogonidae) based on molecular analyses and comparative reevaluation of morphological characters. Zootaxa, 3846, 151-203.

Ng H, Lim K (2014) A preliminary checklist of the cardinalfishes (Actinopterygii: Gobiiformes) of Singapore. Check List, 10, 1061-1070.

Puckridge M, Andreakis N, Appleyard SA, Ward RD (2013) Cryptic diversity in Flathead fishes (Scorpaeniformes: Platycephalidae) across the Indo-West Pacific uncovered by DNA barcoding. Molecular Ecology Resources, 13, 32-42.

Ren ZH, Li F, Wei JL, Lü ZB, Gao YJ, Cong XR (2016) Autumnal species composition and community diversity of nekton in the eastern Bohai Sea. Acta Ecologica Sinica, 36, 5537-5547. (in Chinese with English abstract) [任中华, 李 凡, 魏佳丽, 吕振波, 高彦洁, 从旭日 (2016) 渤海东部海域 秋季底层游泳动物种类组成及群落多样性. 生态学报, 36, 5537-5547.]

Shen GY (1985) Family Apogonidae. In: The Fishes of Fujian Province (Part II) (ed. Zhu YD), pp 45-57. Fujian Science and Technology Press, Fujian. (in Chinese) [沈根媛 (1985) 天竺鲷科. 见: 福建鱼类志下卷(朱元鼎主编), 45-57页. 福 建科学技术出版社, 福州.]

Shen SJ (1984) Synopsis of Fishes of Taiwan, pp. 234-239. Southern Materials Center, INC, Taibei. (in Chinese). [沈世 杰 (1984) 台湾鱼类检索, 234-239页. 南天书局有限公司, 台北.]

Shen SJ (1993) Family Apogonidae. In: Fishes of Taiwan (ed. 
俞正森, 宋娜, 本村浩之, 高天翔 (2021) 中国银口天竺鲷属鱼类的分类厘定. 生物多样性, 29, 971-979. http://www.biodiversityscience.net/CN/10.17520/biods.2020320

Shen SJ), pp. 308-323. Department of Animal Science and Technology, Taiwan University, Taibei. (in Chinese) [沈世 杰 (1993) 天竺鲷科. 见: 台湾鱼类志 (沈世杰主编), 308323页. 台湾大学动物学系, 台北.]

Shen SJ (1993) Fishes of Taiwan pp. 308-323. Department of Animal Science and Technology, Taiwan University, Taibei. (in Chinese) [沈世杰 (1993) 台湾鱼类志, 308-323页. 台湾 大学动物学系, 台北.]

Sun DR, Chen Z (2013) Synopsis of Fishes in the South China Sea, pp. 450-468. China Ocean Press, Beijing. (in Chinese) [孙典荣, 陈铮 (2013) 南海鱼类检索, 450-468页. 海洋出 版社, 北京.]

Wang YK (1958) Taxonomy of Fishes, pp. 290-294. Shanghai Scientific \& Technical Publishers, Shanghai. (in Chinese) [王以康 (1958) 鱼类分类学, 290-294页. 上海科学技术出 版社, 上海.]

Xu XJ (2001) Family Apogonidae. In: The Fauna of Hebei, China, Pisces (Wang SA, Wang ZM, Li GL, Cao YP), pp. 217-218. Hebei Science and Technology Publishing House, Shijiazhuang. (in Chinese). [徐学军 (2001) 天竺鲖科. 见: 河北动物志鱼类(王所安, 王志敏, 李国良, 曹玉萍主编), 217-218页. 河北科学技术出版社, 石家庄.]

Yu CG, Chen QZ, Chen XQ, Ning P, Zheng J (2010) Species composition and quantitative distribution of fish in the Zhoushan fishing ground and its adjacent waters. Oceanologia et Limnologia Sinica, 41, 410-417. (in Chinese with English abstract) [俞存根, 陈全震, 陈小庆, 宁平, 郑基 (2010) 舟山渔场及附近海域鱼类种类组成和数量分布. 海洋与湖沼, 41, 410-417.]

Yu ZS, Song N, Han ZQ, Gao TX, Li PF, Zhou YD (2017) A new record of Jaydia truncata (Perciformes: Apogonidae) from Zhejiang based on morphological characters and DNA barcoding. Oceanological et Limnologia Sinica, 48, 79-85. (in Chinese with English abstract) [俞正森, 宋娜, 韩志强, 高天翔, 李鹏飞, 周永东 (2017) 浙江海域天竺鲷科鱼类新 纪录种一黑边银口天竺鲖 (Jaydia truncata) 形态特征与 DNA条形码研究. 海洋与湖沼, 48, 79-85.]

Yu ZS, Song N, Han ZQ, Gao TX, Shui BN, Gon O (2016) The taxonomic status and sister group relationship of the cardinalfish species Jaydia striatodes (Percomorphaceae: Apogonidae). Zootaxa, 4175, 1-9.

Zhao SL, Xu HX, Zhong JS, Chen J (2016) Marine Fishes of Zhejiang Province. Zhejiang Science and Technology Press, Hangzhou, pp. 596-600. (in Chinese) [赵盛龙, 徐汉祥, 钟 俊生, 陈健 (2016) 浙江海洋鱼类志, 596-600页. 浙江科学 技术出版社, 杭州.]

Zhao SL, Zhong JS (2006) Photographic Guide to Marine Fishes of Zhoushan Waters, pp. 24-25, 103-104. Zhejiang Science and Technology Press, Hangzhou. (in Chinese) [ 赵 盛龙, 钟俊生 (2006) 舟山海域鱼类原色图鉴, 24-25, 103104页. 浙江科学技术出版社, 杭州.] 


\section{附录3 中国银口天竺鲖属鱼类主要形态特征差异分析}

Appendix 3 Morphological comparison of Jaydia species in China

本研究检视中国8种银口天竺鲷鱼类的标本, 并进行详细的比较分析, 各形态特征的比较见表A3-A9及下文描述。

(1)骨学特征。前鳃盖骨的结果与Gon (1997)基本一致。但斑鯺银口天竺鲷的大型个体 (> $110 \mathrm{~mm}$ )前鳃盖骨边缘转折处常具1-3枚弱锯齿。眶下骨、后 题骨、上神经骨和尾神经骨的比较见表A3。黑鰓银口天竺鲷上下领近联合处齿明显膨大, 其他种类仅轻微膨大。

(2)计数特征。胸鯺鯺条数的比较见表A3和表A4。背前鳞数见表A3。鳃耙数是银口天竺鲖属最重要的计数特征. 传统形态学单纯计数上鳃耙数和下鳃 耙数对银口天䇥鲖属鱼类的区分帮助不大, 本研究将鳃耙区分为发达鳃耙和退化鰓耙, 并单独计数角鳃耙数, 其中发达上鳃耙数、角鳃耙数以及发达鳃耙数 等特征能够十分有效地区分本属物种, 退化鳃耙数在区分物种上意义不大(表A5-A9)。相比传统只计数上、下鳃耙数, 精细的鳃耙划分和计数对银口天竺鲖 属鱼类具有明显更好的物种区分效果。

(3)颜色特征。细条银口天竺鲷、新几内亚银口天竺鲷、斑鯺银口天竺鲷无胸部发光器官, 其峡部到胸部无黑色素分布; 其他种类都具有胸部发光器官, 其峡部到胸部都具有黑色素分布。峡部到胸部黑色素的有无和胸部发光器官的有无应为一对相关的特征。黑边银口天竺鲷种团、印度洋银口天竺鲷、横 带银口天筑鲷都具有发光器官, 其腹膜均具黑色素分布; 黑鳃银口天竺鲷具发光器官, 但其腹膜无黑色素分布; 细条银口天矢鲷、新几内亚银口天䇥鲷和斑 鯺银口天䇥鲖都不具有发光器官, 其腹膜无黑色素分布。腹膜斑点的有无和发光器官的有无应是一对相关联的特征。黑色素的分布应对该属鱼类发光具有 一定的作用。其他颜色特征见标本照片及各物种描述。

\section{表A3 中国银口天竺鲷属鱼类形态特征比较}

Table A3 Morphological comparison between Jaydia species of China

\begin{tabular}{|c|c|c|c|c|c|c|c|c|}
\hline 性状 Characters & J. carinata & J. poeciloptera & $J$. lineata & J. novaeguineae & J. striatodes & J. striata & Jaydia sp. & J. truncata \\
\hline 最大体长/mm & 117.9 & 98.2 & 68.0 & 79.7 & 68.4 & 53.1 & 98.6 & 110.5 \\
\hline \multicolumn{9}{|c|}{ 测量性状 (以体长的百分比表示, 圆括号内为平均值, 下同) } \\
\hline 体高 & $30.8-36.8(33.6)$ & $33.5-39.2(35.9)$ & $31.8-40.15(35.8)$ & $33.1-34.1(33.6)$ & $33.55-37.9(35.4)$ & $32.8-35.2(33.6)$ & $27.7-33.2(29.35)$ & $26.7-33.9(30.8)$ \\
\hline 头长 & $37.0-43.5(40.7)$ & $40.5-44.2(41.9)$ & $38.2-45.2(41.1)$ & $40.7-42.7(41.7)$ & $39.6-43.25(41.6)$ & $37.0-41.1(39.6)$ & $39.3-41.9(40.5)$ & $37.0-43.0(41.3)$ \\
\hline 上领长 & $18.8-22.0(20.8)$ & $19.75-21.7(20.8)$ & $18.2-21.4(19.8)$ & $18.1-19.6(18.8)$ & $19.3-21.3(20.3)$ & $19.8-21.5(23.0)$ & $19.1-20.0(19.5)$ & 18.6-21.4 (20.1) \\
\hline 下领长 & $22.2-26.4(23.9)$ & $22.7-25.2(24.3)$ & $20.7-25.8(22.7)$ & $22.3-23.5$ (22.9) & $21.8-23.8$ (22.9) & $22.0-23.9(23.0)$ & 21.6-23.4 (22.8) & $20.3-24.0(23.0)$ \\
\hline 吻长 & $5.9-7.6(6.7)$ & 6.6-7.7 (7.3) & $6.6-8.9(7.3)$ & 7.7-9.0 (8.3) & $6.4-7.4(6.9)$ & $6.3-7.0(6.6)$ & $6.5-7.5$ (6.9) & 6.1-8.6 (7.55) \\
\hline 眼径 & $9.8-12.4(10.7)$ & $10.3-11.6(11.0)$ & 9.3-13.8 (11.0) & $12.4-12.7$ (12.6) & $11.5-13.2(12.3)$ & $12.1-14.0(13.0)$ & $10.7-12.0(11.2)$ & $9.8-12.3$ (10.9) \\
\hline 眼间距 & $8.1-9.9(9.0)$ & $8.5-9.5(9.1)$ & $7.8-10.2(9.1)$ & $7.3-8.3(7.8)$ & $8.1-9.2(8.6)$ & $7.5-8.3(8.0)$ & 7.7-8.6 (8.3) & 7.6-9.8 (9.0) \\
\hline 吻到第一背鯺起点 & $35.1-40.1(37.8)$ & 35.3-39.9 (38.1) & 33.7-39.7 (37.3) & $38.6-39.5$ (39.1) & $36.6-41.1$ (38.7) & $37.1-38.6$ (37.9) & $36.75-38.8(37.6)$ & $34.6-40.0(37.8)$ \\
\hline 吻到第二背鯺起点 & $56.6-64.3(59.5)$ & 58.65-61.3 (59.95) & $55.0-62.7(58.4)$ & & $55.7-62.2(29.9)$ & $57.9-62.1(59.4)$ & $58.6-61.9(60.8)$ & $55.3-63.9(59.6)$ \\
\hline 吻到腹鳍起点 & $30.3-36.9$ (32.9) & $29.3-35.0$ (31.8) & $28.6-36.4$ (31.9) & $31.7-32.6$ (32.2) & $32.9-36.1(34.4)$ & $29.0-34.4(32.2)$ & $30.25-34.5$ (32.9) & $31.3-37.3$ (33.6) \\
\hline 吻到慰鰙起点 & $59.6-69.1(64.3)$ & $60.5-66.75(64.1)$ & $57.4-65.7$ (61.9) & $61.2-61.7$ (61.5) & $62.0-67.15$ (64.8) & $61.7-64.6(62.8)$ & $64.7-67.7(66.2)$ & $62.1-67.4(65.1)$ \\
\hline
\end{tabular}


俞正森, 宋娜, 本村浩之, 高天翔 (2021) 中国银口天竺鲖属鱼类的分类厘定. 生物多样性, 29, 971-979. http://www.biodiversity-science.net/CN/10.17520/biods.2020320

\begin{tabular}{|c|c|c|c|c|c|c|c|c|}
\hline 性状 Characters & J. carinata & J. poeciloptera & J. lineata & J. novaeguineae & J. striatodes & J. striata & Jaydia sp. & J. truncata \\
\hline 最大体长/mm & 117.9 & 98.2 & 68.0 & 79.7 & 68.4 & 53.1 & 98.6 & 110.5 \\
\hline 肛门到臀鯺起点 & $4.3-7.6(5.1)$ & $2.5-4.8(3.8)$ & $3.0-4.4(3.7)$ & $2.6-3.4(3.0)$ & $2.9-4.3(3.5)$ & $3.0-5.0(4.0)$ & $1.9-2.9(2.4)$ & $1.4-3.8(2.7)$ \\
\hline 第一背鯺第一鯺棘长 & $2.8-5.3(3.9)$ & $2.1-4.1(3.2)$ & $2.0-4.1(3.1)$ & 3.0 & $2.7-3.6(3.2)$ & $2.8-4.7(3.6)$ & $2.8-3.9(3.5)$ & $2.5-5.0(3.5)$ \\
\hline 第一背鯺第二鳍棘长 & 7.9-11.4 (9.3) & 7.3-9.5 (8.6) & 8.1-13.6 (10.6) & $8.0-8.3(8.2)$ & $7.1-9.2(8.0)$ & 7.9-9.6 (9.0) & 6.9-9.1 (8.15) & 7.3-10.65 (8.75) \\
\hline 第一背鯺第三鯺棘长 & $12.6-16.1(14.2)$ & 11.1-15.8 (13.5) & $14.0-18.3(16.4)$ & $14.0-15.4(14.7)$ & $12.3-15.8(14.0)$ & $14.1-16.4(15.3)$ & $12.1-13.7(13.2)$ & $11.4-15.1(13.1)$ \\
\hline 第一背鯺第四鳍棘长 & $10.7-18.5$ (16.5) & 13.9-15.8 (15.0) & 15.9-19.2 (17.4) & $15.9-16.0(16.0)$ & 13.4-17.7 (15.85) & $14.4-17.0(16.1)$ & $14.4-16.5$ (15.5) & $12.9-17.6(15.0)$ \\
\hline 第二背鳍鳍棘长 & $11.5-14.9(12.9)$ & 10.1-13.1 (11.3) & $12.4-16.0(13.9)$ & 12.4 & $10.8-13.9(12.1)$ & $12.8-13.4$ (13.2) & 8.4-11.95 (10.3) & $10.4-12.5$ (11.45) \\
\hline 背鯺最长软条长 & $22.5-29.5(25.4)$ & $23.6-25.7(24.7)$ & 22.9-28.2 (26.0) & $24.0-25.0(24.5)$ & $22.3-25.8(24.0)$ & $22.6-25.3(23.8)$ & $22.2-25.3(23.6)$ & $21.6-25.4(24.1)$ \\
\hline 慰鯺第一鯺棘长 & 2.9-4.7 (3.8) & 2.5-3.8 (3.2) & $2.6-5.7(4.2)$ & $3.9-4.6(4.2)$ & $3.0-4.25(3.7)$ & $4.7-5.7(5.1)$ & $2.9-3.5(3.2)$ & $2.6-4.1(3.3)$ \\
\hline 慰鯺第二鳍棘长 & $10.7-15.0(12.2)$ & 10.1-13.7 (11.55) & $11.3-15.0(13.4)$ & $11.5-12.6(12.1)$ & $10.6-13.3(12.0)$ & $12.2-13.8(13.3)$ & 8.5-10.7 (10.0) & $8.7-13.0(10.3)$ \\
\hline 臀鯺最长软条长 & 19.5-25.2 (22.7) & 20.2-23.4 (22.1) & $20.2-25.3$ (23.05) & 22.2 & $20.2-24.1(21.7)$ & $22.2-22.8(22.5)$ & $19.5-21.3(20.4)$ & $19.1-23.2(21.2)$ \\
\hline 胸鯺长 & 20.4-26.8 (23.9) & $23.3-26.5(25.2)$ & $24.0-29.3(26.5)$ & $25.7-26.1(25.9)$ & $23.2-26.0(24.4)$ & $24.5-27.4(25.8)$ & 19.75-22.25 (20.9) & 20.35-23.9 (22.3) \\
\hline 腹鯺长 & 23.4-30.0 (26.5) & $22.8-26.8(24.1)$ & $21.3-26.6(23.5)$ & 23.2-23.8 (23.5) & $20.2-23.0(21.55)$ & $22.0-24.1(22.8)$ & $19.3-22.1$ (21.25) & 19.5-23.9 (22.4) \\
\hline 腹鯺鯺棘长 & 10.5-15.3 (12.5) & $9.55-12.4(10.7)$ & $11.1-16.3(14.0)$ & 13.7 & 11.9-14.7 (12.8) & $13.0-14.7$ (13.8) & $11.5-12.9(12.3)$ & $10.9-14.7$ (12.5) \\
\hline 尾柄长 & $19.2-24.1(22.1)$ & $19.7-24.0(21.7)$ & $21.6-27.6(24.4)$ & $22.7-24.5(23.6)$ & $22.25-25.6(23.5)$ & $20.1-25.3(23.2)$ & $20.5-24.1(21.8)$ & $19.5-24.2(22.2)$ \\
\hline 尾柄高 & 14.1-17.4 (15.6) & $14.9-16.6(15.8)$ & 13.5-17.1 (15.0) & 16.8-17.1 (16.9) & $15.2-17.25$ (16.1) & $14.0-16.5$ (15.4) & 13.8-16.3 (15.1) & $13.05-15.9(14.7)$ \\
\hline \multicolumn{9}{|c|}{ 计数性状 (圆括号内为通常的数值, 下同)和解剖性状 } \\
\hline 背鳍鳍条数 & VII + I, 9 & $\mathrm{VII}+\mathrm{I}, 9$ & $\mathrm{VII}+\mathrm{I}, 9$ & $\mathrm{VII}+\mathrm{I}, 9$ & $\mathrm{VII}+\mathrm{I}, 9$ & VII + I, 9 & VII + I, 9 & VII + I, 9 \\
\hline 臀鳍鳍条数 & II, 8 & II, 8 & II, 8 & II, 8 & II, 8 & II, 8 & II, 8 & II, 8 \\
\hline 胸鯺鳍条数 & $16-17(16)$ & 15-17 (16) & 14-16 (15) & 16-17 (16) & 15 & 15 & $16-17$ & 16-17 (17) \\
\hline 侧线鳞数 & $24+3$ & $24+3$ & $24+3$ & - & $24+3$ & $24+3$ & $24+3$ & $24+3$ \\
\hline 背前鳞数 & $2-3$ & $4-5$ & $3-4$ & $4-5$ & 4 & $3-4$ & 4 & $3-4$ \\
\hline 总鳃耙数 & \multicolumn{2}{|c|}{$3-4+11-13=14-162-4+11-12=13-16$} & $\begin{array}{l}2-5+11-14=15-19 \\
(3-4+12-13=16-18)\end{array}$ & $4+11=15$ & $4-6+11-13=16-19$ & $3-4+11-13=15-17$ & $3+11-12=14-15$ & $3-4+11-13=14-17$ \\
\hline 发达鳃耙数 & $1+9-11$ & $1+9-11$ & $\begin{array}{l}1-3+11-13=13-15 \\
(2+11-12)\end{array}$ & $2+9$ & $2-3(3)+11-12=14-15$ & $2+11$ & $1+9-10$ & $1+9-11$ \\
\hline 角鳃耙数 & $8-9(8)$ & 8 & $8-9(9)$ & 8 & 9 & 9 & 8 & 8-9 (8) \\
\hline 前鳃盖骨边缘/脊边缘 & 光滑/光滑 & 光滑/光滑 & 弱锯齿状/光滑 & 弱锯齿状/光滑 & 弱锯齿状/光滑 & 弱锯齿状/光滑 & 弱锯齿状/弱锯齿状 & 弱锯齿状/弱锯齿状 \\
\hline 第三眶下骨边缘 & 光滑 & 光滑 & 光滑 & 光滑 & 光滑 & 光滑 & 弱锯齿状 & 弱锯齿状 \\
\hline 后颢骨边缘 & 光滑 & 光滑 & 弱锯齿状 & 弱锯齿状 & 弱锯齿状 & 弱锯齿状 & 弱锯齿状 & 弱锯齿状 \\
\hline 上神经骨数 & 2 & 3 & 3 & 3 & 3 & 3 & 3 & 3 \\
\hline 尾神经骨数 & 2 & 2 & 0 & 0 & 0 & 0 & 2 & 2 \\
\hline
\end{tabular}


俞正森, 宋娜, 本村浩之, 高天翔 (2021) 中国银口天竺鲷属鱼类的分类厘定. 生物多样性, 29, 971-979. http://www.biodiversityscience.net/CN/10.17520/biods.2020320

表A4 中国银口天筷鲷属鱼类胸鯺条数

Table A4 Pectoral fin-rays counts of Jaydia species of China

\begin{tabular}{|c|c|c|c|c|c|c|c|c|c|c|c|c|}
\hline \multirow[t]{2}{*}{ 种类 Species } & \multicolumn{6}{|c|}{ 左胸鯺条数 Left pectoral fin rays } & \multicolumn{6}{|c|}{ 右胸鯺条数 Right pectoral fin rays } \\
\hline & 14 & 15 & 16 & 17 & 18 & $\mathrm{n}$ & 14 & 15 & 16 & 17 & 18 & $\mathrm{n}$ \\
\hline J. carinata & & & 48 & 12 & & 60 & & & 45 & 15 & & 60 \\
\hline J. poeciloptera & & 1 & 37 & 1 & & 39 & & 2 & 34 & 1 & & 37 \\
\hline J. lineata & 2 & 93 & 5 & & & 100 & 2 & 88 & 5 & & & 95 \\
\hline J. novaeguineae & & & 3 & 1 & & 4 & & & 3 & 1 & & 4 \\
\hline Jaydia sp. & & & 3 & 3 & & 6 & & & 2 & 3 & & 5 \\
\hline J. striatodes & & 28 & & & & 28 & & 28 & & & & 28 \\
\hline J. striata & & 8 & & & & & & 7 & & & & \\
\hline J. truncata & & & 8 & 41 & 2 & 51 & & & 8 & 41 & 2 & 51 \\
\hline
\end{tabular}

表A5 中国银口天竺鲖属鱼类总鳃耙数和发达鳃耙数

Table A5 Counts of total gill rakers and developed gill rakers of Jaydia species of China

\begin{tabular}{|c|c|c|c|c|c|c|c|c|c|c|c|c|c|c|c|}
\hline \multirow[t]{2}{*}{ 种类 Species } & \multicolumn{8}{|c|}{ 总鳃耙数 Total gill rakers } & \multicolumn{7}{|c|}{ 发达鳃耙数 Developed gill rakers } \\
\hline & 13 & 14 & 15 & 16 & 17 & 18 & 19 & $\mathrm{n}$ & 10 & 11 & 12 & 13 & 14 & 15 & $\mathrm{n}$ \\
\hline J. carinata & & 3 & 41 & 16 & & & & 60 & 5 & 48 & 7 & & & & 60 \\
\hline J. poeciloptera & 1 & 5 & 26 & 7 & & & & 39 & 1 & 36 & 2 & & & & 39 \\
\hline J. lineata & & & 1 & 19 & 44 & 37 & 2 & 103 & & & & 32 & 63 & 8 & 103 \\
\hline J. novaeguineae & & & 4 & & & & & 4 & & 4 & & & & & 4 \\
\hline Jaydia sp. & & 1 & 4 & & & & & 5 & 1 & 4 & & & & & 5 \\
\hline J. striatodes & & & & 1 & 7 & 14 & 1 & 23 & & & & & 8 & 15 & 23 \\
\hline J. striata & & & 2 & 5 & 1 & & & 8 & & & & 8 & & & 8 \\
\hline J. truncata & & 2 & 14 & 27 & 3 & & & 46 & 5 & 41 & 3 & & & & 49 \\
\hline
\end{tabular}

表A6 中国银口天竺鲷属鱼类上鳃耙数和下鳃耙数

Table A6 Counts of upper rakers and lower rakers of Jaydia species of China

\begin{tabular}{|c|c|c|c|c|c|c|c|c|c|c|c|c|}
\hline \multirow[t]{2}{*}{ 种类 Species } & \multicolumn{6}{|c|}{ 上鳃耙数 Upper gill rakers } & \multicolumn{6}{|c|}{ 下鳃耙数 Lower gill rakers } \\
\hline & 2 & 3 & 4 & 5 & 6 & $\mathrm{n}$ & 11 & 12 & 13 & 14 & 15 & $\mathrm{n}$ \\
\hline J. carinata & & 45 & 15 & & & 60 & 5 & 52 & 3 & & & 60 \\
\hline J. poeciloptera & 1 & 30 & 8 & & & 39 & 7 & 32 & & & & 39 \\
\hline J. lineata & 2 & 38 & 60 & 2 & & 102 & 2 & 39 & 58 & 2 & & 101 \\
\hline J. novaeguineae & & & 4 & & & 4 & 4 & & & & & 4 \\
\hline Jaydia sp. & & 5 & & & & 5 & 2 & 3 & & & & 5 \\
\hline J. striatodes & & & 2 & 20 & 1 & 23 & 1 & 5 & 17 & & & 23 \\
\hline J. striata & & 1 & 7 & & & 8 & 2 & 5 & 1 & & & 8 \\
\hline J. truncata & & 12 & 37 & & & 49 & 11 & 33 & 5 & & & 49 \\
\hline
\end{tabular}

表A7 中国银口天竺鲖属鱼类发达上鳃耙数和发达下鳃耙数

Table A7 Counts of upper developed gill rakers and lower developed gill rakers of Jaydia species of China

\begin{tabular}{|c|c|c|c|c|c|c|c|c|c|c|}
\hline \multirow[t]{2}{*}{ 种类 Species } & \multicolumn{4}{|c|}{ 发达上鳃耙数 Developed upper gill rakers } & \multicolumn{6}{|c|}{ 发达下鰓耙数 Developed lower gill rakers } \\
\hline & 1 & 2 & 3 & $\mathrm{n}$ & 9 & 10 & 11 & 12 & 13 & $\mathrm{n}$ \\
\hline J. carinata & 60 & & & 60 & 5 & 48 & 7 & & & 60 \\
\hline J. poeciloptera & 39 & & & 39 & 1 & 36 & 2 & & & 39 \\
\hline J. lineata & 2 & 94 & 6 & 102 & & & 32 & 67 & 2 & 101 \\
\hline J. novaeguineae & & 4 & & 4 & 4 & & & & & 4 \\
\hline Jaydia sp. & 5 & & & 5 & 1 & 4 & & & & 5 \\
\hline J. striatodes & & 1 & 22 & 23 & & & 7 & 16 & & 23 \\
\hline J. striata & & 8 & & 8 & & & 8 & & & 8 \\
\hline J. truncata & 49 & & & 49 & 4 & 42 & 3 & & & 49 \\
\hline
\end{tabular}


俞正森, 宋娜, 本村浩之, 高天翔 (2021) 中国银口天竺鲷属鱼类的分类厘定. 生物多样性, 29, 971-979. http://www.biodiversityscience.net/CN/10.17520/biods.2020320

表A8 中国银口天竺鲷属鱼类角鳃耙数

Table A8 Counts of ceratobranchial rakers of Jaydia species of China

\begin{tabular}{llll}
\hline 种类 Species & 角鰓耙数 Ceratobranchial rakers & \\
\hline & 8 & 9 & $\mathrm{n}$ \\
\hline J. carinata & 58 & 2 & 60 \\
J. poeciloptera & 39 & 99 & 39 \\
J. lineata & 3 & & 102 \\
J. novaeguineae & 4 & 4 & 5 \\
Jaydia sp. & 5 & 23 & 23 \\
J. striatodes & & 8 & 8 \\
J. striata & 48 & 1 & 49 \\
J. truncata & & & \\
\hline
\end{tabular}

表A9 中国银口天竺鲖属鱼类退化上鳃耙数和退化下鳃耙数

Table A9 Counts and averages of upper rudiments and lower rudiments of Jaydia species of China

\begin{tabular}{|c|c|c|c|c|c|c|c|c|c|c|c|c|}
\hline \multirow{2}{*}{ 种类 Species } & \multicolumn{6}{|c|}{ 退化上鳃耙数 Upper rudiments } & \multicolumn{6}{|c|}{ 退化下鳃耙数 Lower rudiments } \\
\hline & 1 & 2 & 3 & 4 & 平均值 & $\mathrm{n}$ & 0 & 1 & 2 & 3 & 平均值 & $\mathrm{n}$ \\
\hline J. carinata & & 45 & 15 & & 2.3 & 60 & & 10 & 42 & 7 & 1.9 & 59 \\
\hline J. poeciloptera & 1 & 31 & 8 & & 2.2 & 40 & & 9 & 29 & 1 & 1.8 & 39 \\
\hline J. lineata & 4 & 41 & 56 & 2 & 2.5 & 103 & 15 & 79 & 10 & & 1.0 & 104 \\
\hline J. novaeguineae & & 4 & & & 2 & 4 & & & 4 & & 2 & 4 \\
\hline J. striatodes & 2 & 20 & & 1 & 2 & 23 & 3 & 17 & 3 & & 1 & 23 \\
\hline J. striata & 1 & 7 & & & 1.9 & 8 & 2 & 5 & 1 & & 0.9 & 8 \\
\hline Jaydia sp. & & 5 & & & 2 & 5 & & 1 & 4 & & 1.8 & 5 \\
\hline J. truncata & & 12 & 37 & & 2.8 & 49 & & 12 & 29 & 8 & 1.9 & 49 \\
\hline
\end{tabular}

